\title{
The X-43A Flush Airdata Sensing System Flight Test Results
}

\author{
Ethan Baumann, ${ }^{*}$ Joseph W. Pahle, ${ }^{\dagger}$ and Mark C. Davis ${ }^{\ddagger}$ \\ NASA Dryden Flight Research Center, Edwards, California, 93523 \\ and \\ John Terry White ${ }^{\S}$ \\ Tybrin Corporation, Edwards, California, 93523
}

\begin{abstract}
The National Aeronautics and Space Administration (NASA) has flight-tested a flush airdata sensing (FADS) system on the Hyper-X Research Vehicle (X-43A) at hypersonic speeds during the course of two successful flights. For this series of tests, the FADS system was calibrated to operate between Mach 3 and Mach 8, and flight test data was collected between Mach 1 and Mach 10. The FADS system acquired pressure data from surfacemounted ports and generated a real-time angle-of-attack $(\alpha)$ estimate on board the $\mathrm{X}-43 \mathrm{~A}$. The collected data were primarily intended to evaluate the FADS system performance, and the estimated $\alpha$ was used by the flight control algorithms on the X-43A for only a portion of the first successful flight. This paper provides an overview of the FADS system and $\alpha$ estimation algorithms, presents the in-flight $\alpha$ estimation algorithm performance, and provides comparisons to wind tunnel results and theory. Results indicate that the FADS system adequately estimated the $\alpha$ of the vehicle during the hypersonic portions of the two flights.
\end{abstract}

\section{Nomenclature}

$\begin{array}{ll}\mathrm{AMW} & =\text { all-moving wing } \\ \mathrm{BET} & =\text { best estimated trajectory } \\ \mathrm{CFD} & =\text { computational fluid dynamics } \\ \mathrm{C}_{\mathrm{P} 24} & \text { ports } 2 \text { and } 4 \text { differential pressure coefficient } \\ \mathrm{C}_{\mathrm{P} 25} & =\text { ports } 2 \text { and } 5 \text { differential pressure coefficient } \\ \mathrm{C}_{\mathrm{P} 35} & =\text { ports } 3 \text { and } 5 \text { differential pressure coefficient } \\ \mathrm{DB} & =\text { database } \\ \mathrm{DFRC} & =\text { Dryden Flight Research Center } \\ \text { deg } & =\text { degree } \\ \text { FADS } & \text { flush airdata sensing } \\ \text { FADS1 } & =\text { angle-of-attack estimate from FADS pressure ports } 2 \text { and } 4, \text { deg } \\ \text { FADS2 } & =\text { angle-of-attack estimate from FADS pressure ports } 3 \text { and } 5, \text { deg } \\ \text { FADS3 } & =\text { angle-of-attack estimate from FADS pressure ports } 2 \text { and } 5, \text { deg } \\ \mathrm{ft} & =\text { feet } \\ \mathrm{HXLV} & =\text { Hyper-X Launch Vehicle } \\ \mathrm{HXRV} & =\text { Hyper-X Research Vehicle } \\ \text { INS } & =\text { inertial navigation system } \\ \text { in. } & =\text { inch }\end{array}$

\footnotetext{
* Aerospace Engineer, Controls and Dynamics Branch, P.O. Box 273/MS 4840D, AIAA Member.

${ }^{\dagger}$ Aerospace Engineer, Controls and Dynamics Branch, P.O. Box 273/MS 4840D, AIAA Senior Member.

*Aerospace Engineer, Aerodynamics and Propulsion Branch, P.O. Box 273/MS 2228, AIAA Member.

$\S$ Aerospace Engineer, P.O. Box 273/MS 4830D, AIAA Senior Member.
} 


$\begin{array}{ll}\mathrm{lb} & =\text { pound } \\ \mathrm{Max} & =\text { maximum } \\ \mathrm{Min} & =\text { minimum } \\ \mathrm{NASA} & =\text { National Aeronautics and Space Administration } \\ \mathrm{PID} & =\text { parameter identification } \\ \mathrm{PPT} & =\text { precision pressure transducer } \\ \mathrm{P}_{2} & =\text { port } 2 \text { pressure reading, psf } \\ \mathrm{P}_{3} & =\text { port } 3 \text { pressure reading, psf } \\ \mathrm{P}_{4} & =\text { port } 4 \text { pressure reading, psf } \\ \mathrm{P}_{5} & =\text { port } 5 \text { pressure reading, psf } \\ \mathrm{psf} & =\text { pounds per square foot } \\ \text { scramjet } & =\text { supersonic combustion ramjet } \\ \mathrm{TPS} & =\text { thermal protection system } \\ \mathrm{X} / \mathrm{L} & =\text { fraction of reference length } \\ \overline{\mathrm{q}} & =\text { dynamic pressure, } \text { psf } \\ \alpha & =\text { angle of attack, deg } \\ \beta & =\text { angle of sideslip, deg }\end{array}$

\section{Introduction}

$\mathrm{T}$ HE X-43A was the first free-flying, airframe-integrated supersonic combustion ramjet (scramjet) vehicle to be flight tested. The vehicles were successfully flown twice and demonstrated scramjet operation at nearly Mach 7 and nearly Mach 10. The X-43A flight vehicles contained a flush airdata sensing (FADS) system, which obtained surface-mounted pressure port readings throughout both flights. The FADS system was a research element intended to demonstrate a real-time angle-of-attack $(\alpha)$ estimation algorithm on a sharp-nosed hypersonic vehicle.

In general, scramjet performance is highly sensitive to $\alpha$. An accurate, real-time method of estimating $\alpha$ can ensure optimal scramjet performance. The ability to accurately estimate $\alpha$ solely from the inertial navigation system (INS) can be difficult because of atmospheric variations, winds, and sensor installation and performance. Strict requirements to measure and control $\alpha$ for optimal scramjet operation led to the development of a research FADS system for the $\mathrm{X}-43 \mathrm{~A}^{1}$ to explore the concept. The $\alpha$ measurement and control requirement varied for the different mission phases, but the general requirement was to measure and control the vehicle to an $\alpha$ which was within $0.5^{\circ}$ of the true $\alpha$. Prior to the flights, the real-time $\alpha$ estimation algorithms were not deemed mature enough to replace or supplement the inertial $\alpha$ measurement during the scramjet engine tests. However, the algorithms were active during both flights and used to correct the inertial $\alpha$ measurement during the post-engine test portion of the X-43A Mach 7 mission. The scramjet engines tested on the X-43A flight vehicles were designed with operating margin at the engine test points, which resulted in the accuracy of the INS $\alpha$ estimate being adequate during the short duration test points.

This paper briefly discusses the real-time $\alpha$ estimation algorithms. The data collected during the ascent and post-engine test portions of the Mach 7 and Mach 10 missions are presented along with the in-flight performance of the real-time $\alpha$ estimation algorithm. Post-flight updates to the FADS system pressure models are discussed along with performance of an updated real-time algorithm.

\section{Project Description}

The goal of the National Aeronautics and Space Administration (NASA) Hyper-X program was to demonstrate an advanced, airframe-integrated, airbreathing, hypersonic propulsion system in flight, thus validating the supporting design tools and technologies. ${ }^{2,3}$ The program sought to design, build, and flight-test a series of three small, autonomous, scramjet-powered Hyper-X Research Vehicles (HXRV), designated X-43A, at Mach 7 and Mach 10. Two of the vehicles were intended for missions at Mach 7, and one vehicle was intended for a mission at Mach 10. The first flight was intended to reach Mach 7 and was attempted on June 2, 2001. The Hyper-X Launch Vehicle (HXLV), used to boost the HXRV to the test condition, lost control shortly after launch resulting in the loss of both the HXLV and HXRV. ${ }^{4}$ During the second flight, hereafter referred to as the "Mach 7 mission," flown on March 27, 2004, the HXRV successfully demonstrated the in-flight operation of the scramjet. ${ }^{5}$ All of the goals for that mission were achieved, including positive acceleration of the vehicle by the scramjet. The third and final flight, 
hereafter referred to as the "Mach 10 mission," was flown on November 16, 2004, and all of the goals for this mission were also accomplished. ${ }^{6}$ During both successful missions, the HXRV was in controlled autonomous flight from the point of separation from the HXLV to splashdown in the Pacific Ocean. ${ }^{7,8}$

\section{Hyper-X Research Vehicle Description}

As shown in Fig. 1, the HXRV was a sharp-nosed unmanned autonomous vehicle that measured approximately $12 \mathrm{ft}$ long and $5 \mathrm{ft}$ wide, and weighed approximately $3000 \mathrm{lb}$. All three vehicles had the same outer mold line; the primary difference among the vehicles was the internal engine flowpaths. The scramjet engine was attached to the underside of the HXRV and contained a cowl door on the leading edge of the engine. The cowl door allowed air to flow through the engine only during the scramjet test, and was otherwise closed. The HXRV had four control surface effectors: a left and right all-moving wing (AMW) used to control the pitch and roll axes, and twin rudders used to control the yaw axis. The nose and wing leading edges were carbon-carbon composites.

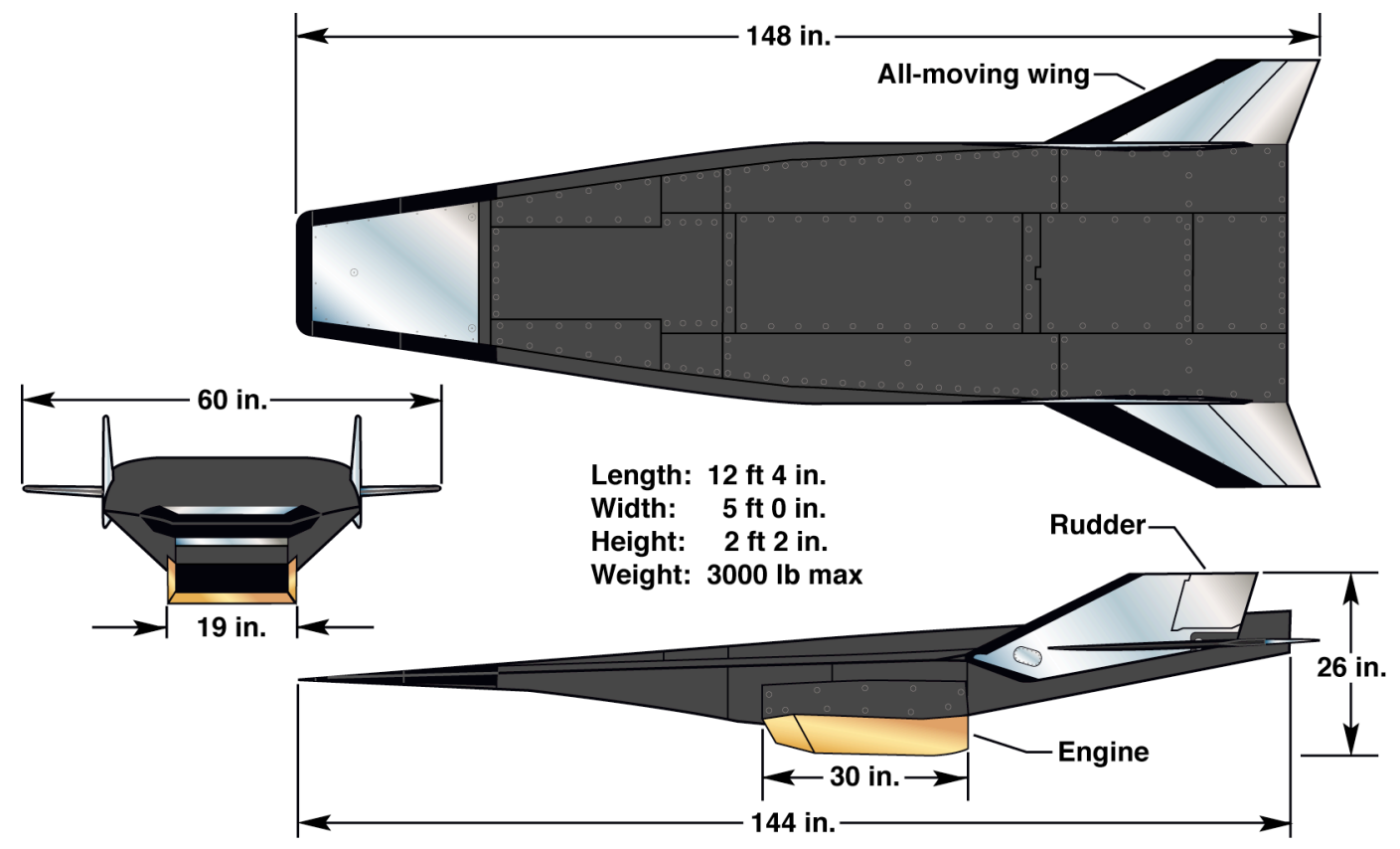

Figure 1. Hyper-X Research Vehicle three-view.

\section{Hyper-X Research Vehicle Mission Description}

The HXRV mission profiles were similar for the Mach 7 and Mach 10 missions. The principal difference between the two flights was the higher Mach number attained during the Mach 10 mission, which resulted in a correspondingly longer descent trajectory. Figure 2 shows an overview of the HXRV mission. The launch, scramjet experiment, and descent portions of the mission were conducted off the coast of southern California. The entire configuration, known as the X-43A stack, was carried under the wing of the NASA Dryden Flight Research Center (DFRC) NB-52B (The Boeing Company, Chicago, Illinois), ship number 008. The HXRV was boosted to the test condition by the HXLV, a modified Pegasus ${ }^{\circledR}$ (Orbital Sciences Corporation, Dulles, Virginia) rocket. During both missions, the HXLV propelled the X-43A stack to a separation altitude of approximately $100,000 \mathrm{ft}$ and a dynamic pressure, $\overline{\mathrm{q}}$, of approximately $1000 \mathrm{psf}$. The HXRV separated at Mach 6.9 during the Mach 7 mission and at Mach 9.7 during the Mach 10 mission. Several seconds after separation the cowl door was opened, the vehicle was stabilized at the desired test condition, and the scramjet engine test was conducted. The scramjet experiment phase lasted approximately $45 \mathrm{~s}$ for the Mach 7 mission and $30 \mathrm{~s}$ for the Mach 10 mission. Following the primary mission, the cowl door was closed and an unpowered trajectory was flown to a splashdown into the Pacific Ocean. During the descent portion of the two missions, a series of parameter identification (PID) maneuvers were performed at every integer Mach number down to Mach 2. ${ }^{10,11}$ These maneuvers began at Mach 5 during the Mach 7 mission and at Mach 8 during the Mach 10 mission. The Mach 7 mission PID maneuvers consisted of a series of step inputs, frequency sweeps, and an $\alpha$ sweep. The Mach 10 mission PID maneuvers consisted of two sets of frequency 
sweeps. The flight data shown in this paper are from the boosted ascent and unpowered post-experiment descent portions of these flights with the cowl door closed.

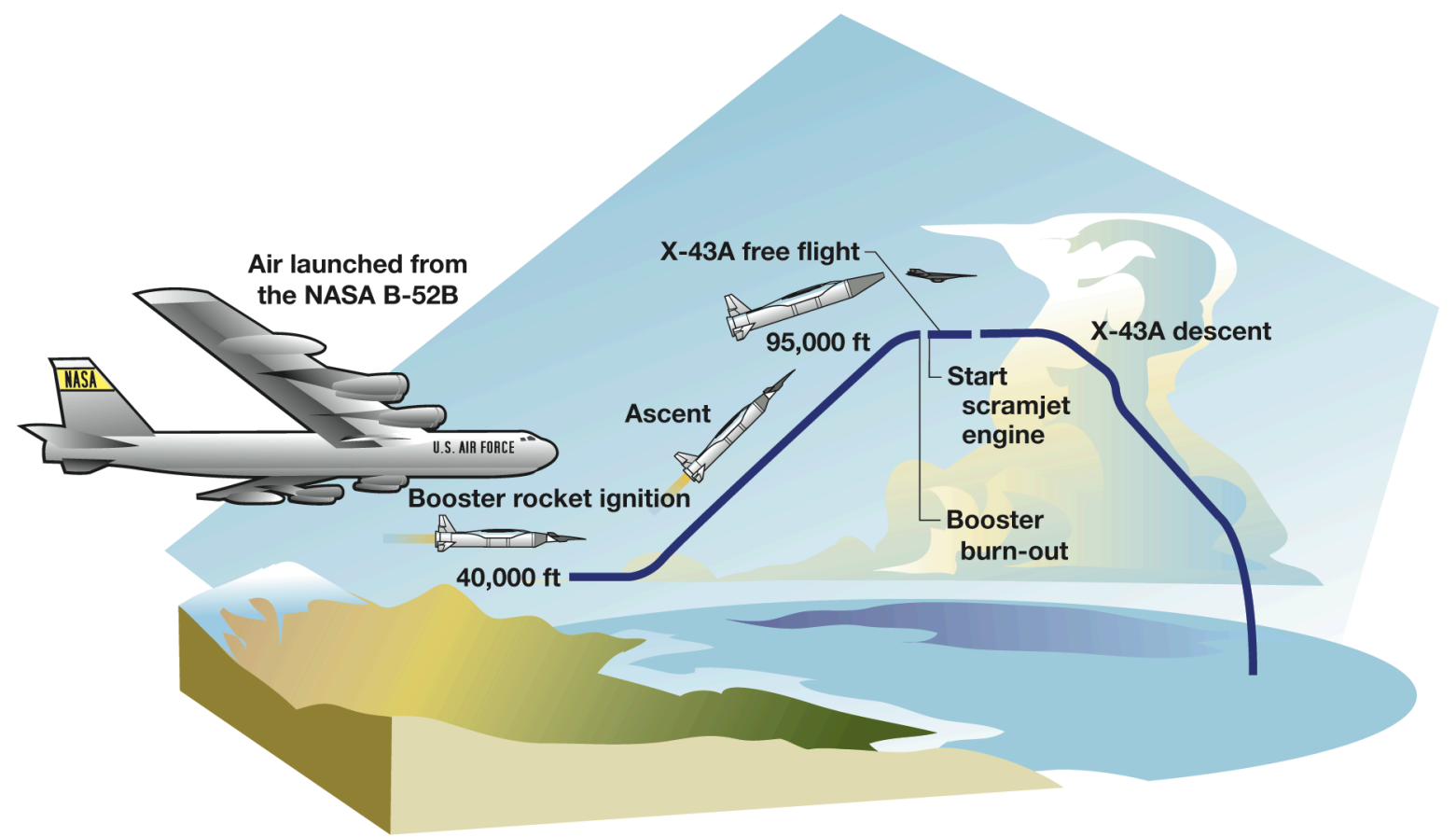

Figure 2. Hyper-X flight trajectory.

\section{FADS Architecture Overview}

The pressure port layout for the FADS system is discussed in detail in Ref. 1. The architecture details are summarized in this section. A matrix of nine pressure ports was used to sense the airdata parameters. Figure 3 shows the locations of these ports on the vehicle forebody. The pressure ports on the upper and lower ramp surfaces had a diameter of 0.04 in., and the pressure port size on the leading edge and sides of the vehicle had a diameter of $0.02 \mathrm{in}$. to limit stagnation heating effects. All pressure ports were drilled normal to the surface. The four ports along the centerline of the upper and lower surface (ports 2-5) were used to indirectly estimate the $\alpha$ in real time. The remaining five pressure ports were intended for post-flight evaluation of the total pressure (port 1), and to indirectly estimate the angle of sideslip, $\beta$ (ports 6-9). 

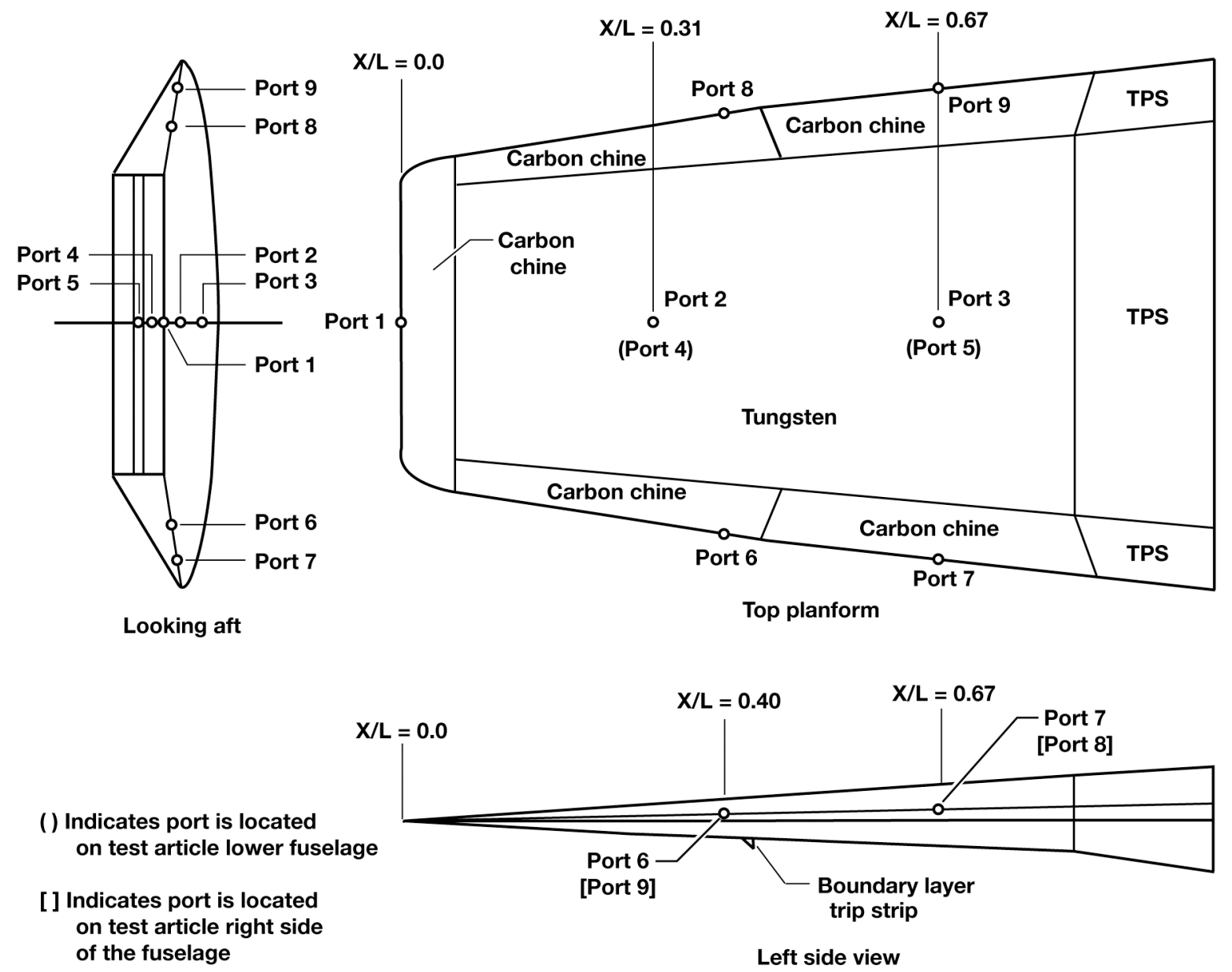

Figure 3. FADS system port layout.

The nine pressures were sensed using a combination of absolute and differential precision pressure transducers (PPT) manufactured by Honeywell International Inc. (Morris Township, New Jersey). All of the PPTs had serial digital outputs, which were connected through an individually addressable, multidrop RS-485 bus. The sensors also provided an optional analog output. The PPT digital output was the primary signal used in the real-time and postflight algorithms. The analog signal was recorded only for post-flight analysis and provided data redundancy upon digital signal failure.

Figure 4 shows the layout of these sensors. Differences between the pairs of upper and lower ramp surface pressures (ports 2 and 4, ports 3 and 5) were sensed by differential pressure transducers to provide a high accuracy and high resolution measurement for use by the real-time $\alpha$ algorithm. Ports 2 and 5 were also teed to an absolute pressure transducer that allowed the absolute pressure level at these ports to be sensed. This combination of absolute and differential ports allowed for a calculation or measurement of the absolute pressure at each port while retaining the high accuracy differential measurements for the $\alpha$ algorithm. Figure 5 shows the underside of the X-43A forebody, and indicates the locations of ports 4 and 5 and the boundary layer trip strip location between the two ports. ${ }^{1}$ 

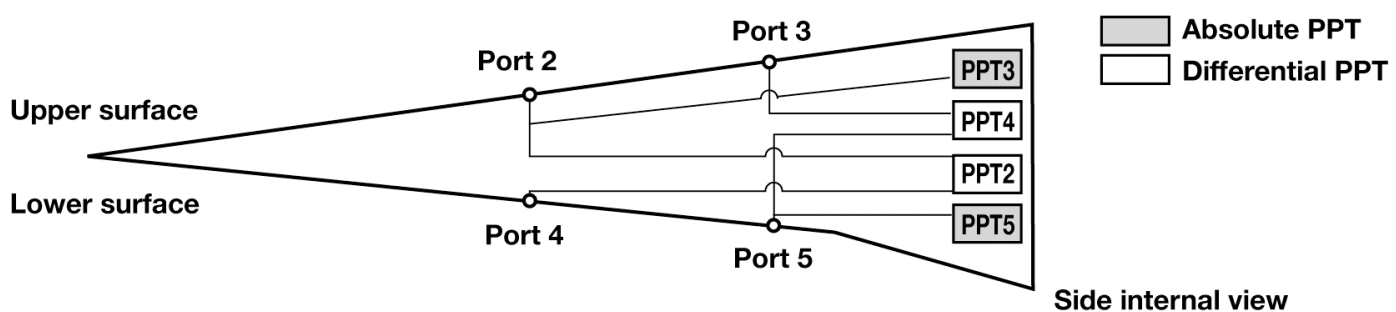

Side internal view

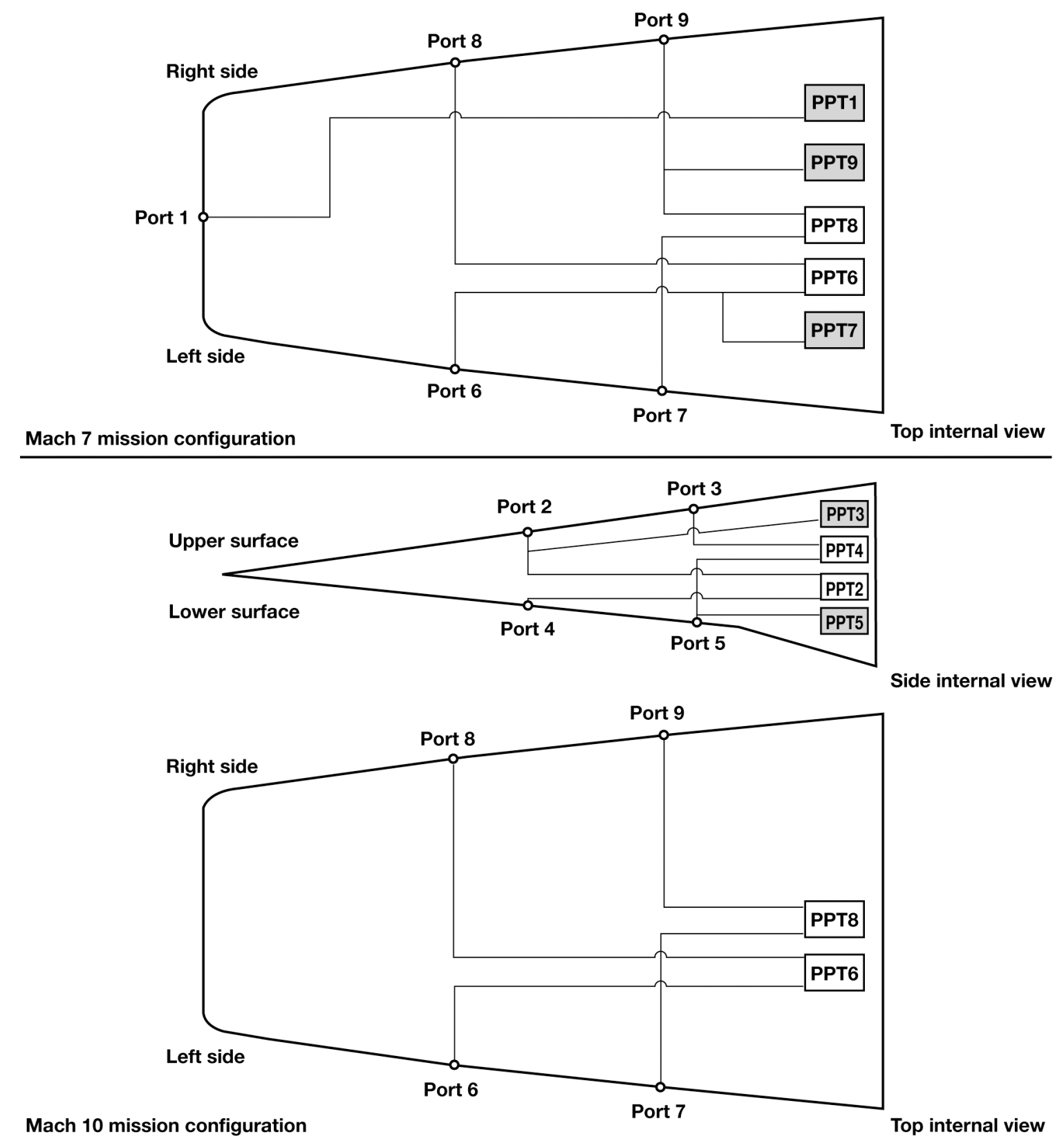

Figure 4. FADS system port and PPT layout for the Mach 7 and Mach 10 missions. 


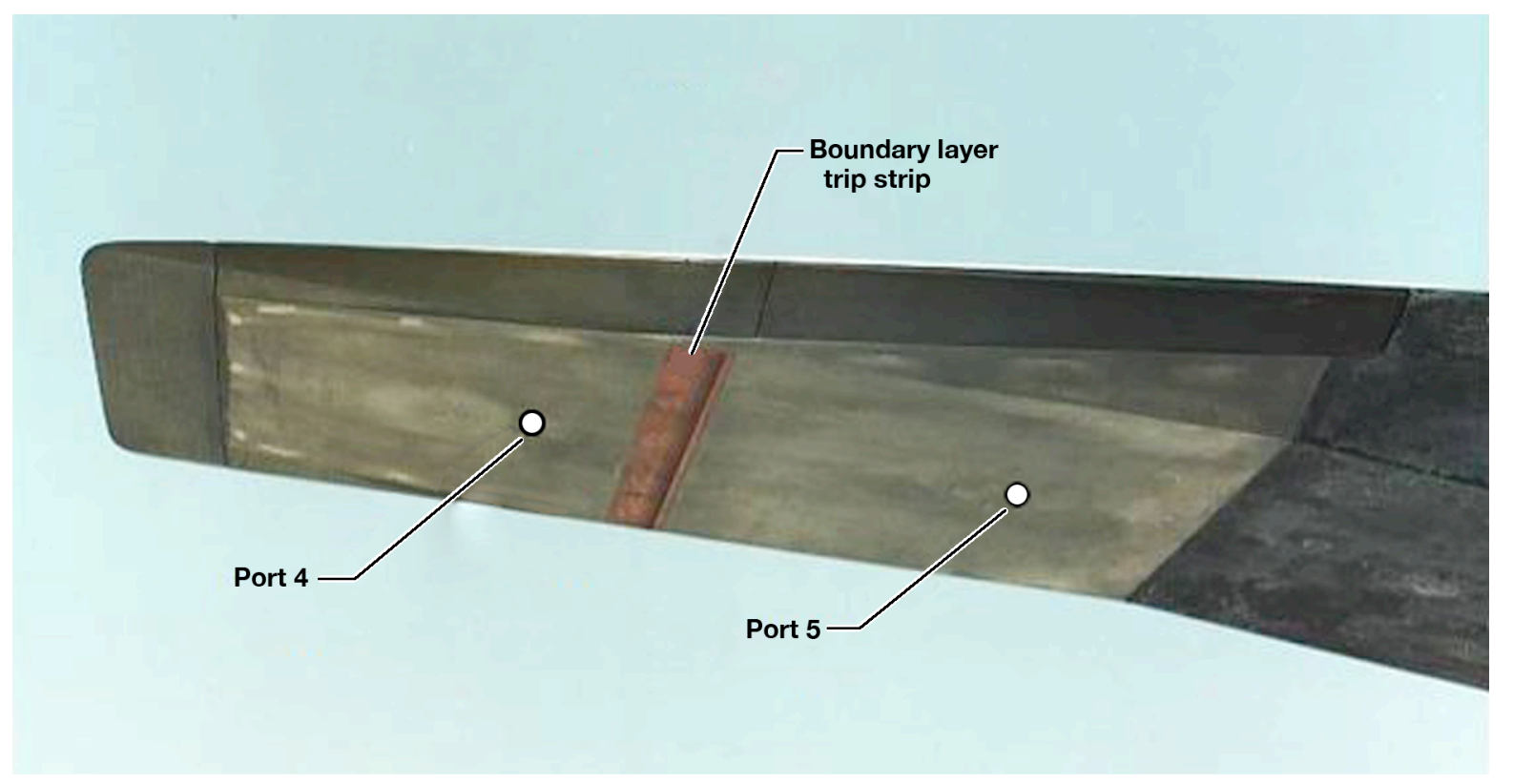

Figure 5. X-43A lower surface showing the locations of ports 4 and 5 and the boundary layer trip strip.

The forebody side ports (ports 6-9) were sensed in a similar manner to the ports along the centerline. A real-time algorithm was not created to estimate $\beta$ from the port 6-9 readings. The single total pressure (port 1) located in the carbon-carbon composite leading edge was sensed using an absolute pressure transducer.

After the Mach 7 mission, the leak rate for the ports installed in the carbon-carbon composite leading edges was discovered to be unacceptably high because of the porosity of the material; hence the data were of little use. For the Mach 10 mission, the absolute pressure transducers that were intended to indirectly estimate $\beta$ and measure the total pressure were replaced with ballast, because the ports associated with these absolute pressure transducers were located in the carbon-carbon composite leading edges. The port locations and PPT configuration used for the $\alpha$ estimation were the same for the Mach 7 and Mach 10 missions. Table 1 lists the PPTs, associated pressure ports, sensor range and accuracy, and flights for which the data are available.

Table 1. FADS system pressure ports.

\begin{tabular}{|c|c|c|c|c|c|c|c|c|}
\hline \multirow{2}{*}{ Sensor } & \multirow{2}{*}{ Port(s) } & \multirow{2}{*}{$\begin{array}{c}\text { Parameter } \\
\text { sensed }\end{array}$} & \multirow{2}{*}{ Sensor type } & \multicolumn{2}{|c|}{ Range, $\mathrm{lbf} / \mathrm{ft}^{2}$} & \multirow{2}{*}{$\begin{array}{c}\text { Accuracy, } \\
\mathrm{lbf} / \mathrm{ft}^{2}\end{array}$} & \multicolumn{2}{|c|}{ Data collected } \\
\hline & & & & Min & $\operatorname{Max}$ & & Flight 2 & Flight 3 \\
\hline PPT 1 & 1 & Total pressure & Absolute & 0 & 2160 & 0.54 & $\bar{X}$ & \\
\hline PPT 2 & 2,4 & $\alpha$ & Differential & -720 & 720 & 0.18 & $\mathrm{X}$ & $\mathrm{X}$ \\
\hline PPT 3 & 2 & $\alpha$ & Absolute & 0 & 2160 & 0.54 & $\mathrm{X}$ & $\mathrm{X}$ \\
\hline PPT 4 & 3,5 & $\alpha$ & Differential & -720 & 720 & 0.18 & $\mathrm{X}$ & $\mathrm{X}$ \\
\hline PPT 5 & 5 & $\alpha$ & Absolute & 0 & 2160 & 0.54 & $\mathrm{X}$ & $\mathrm{X}$ \\
\hline PPT 6 & 6,8 & $\beta$ & Differential & -720 & 720 & 0.18 & $\mathrm{X}$ & $\mathrm{X}$ \\
\hline PPT 7 & 6 & $\beta$ & Absolute & 0 & 2160 & 0.54 & $\mathrm{X}$ & \\
\hline PPT 8 & 7,9 & $\beta$ & Differential & -720 & 720 & 0.18 & $\bar{X}$ & $\bar{X}$ \\
\hline PPT 9 & 9 & $\beta$ & Absolute & 0 & 2160 & 0.54 & $\bar{X}$ & \\
\hline
\end{tabular}

\section{FADS $\alpha$ Estimation Algorithms}

Pressure port data were collected throughout the two missions, including the captive carry, ascent, engine experiment, and descent phases. From the FADS system layout, five separate airdata parameters can theoretically be estimated: total pressure, static pressure, $\alpha, \overline{\mathrm{q}}$, and $\beta$. Real-time algorithms were developed for both $\alpha$ and $\overline{\mathrm{q}}$ 
estimation. The performance of the $\overline{\mathrm{q}}$ estimation algorithm is being investigated and is beyond the scope of this paper. The real-time FADS $\alpha$ estimation algorithm was intended for use between Mach 3 and Mach 8, because valid wind tunnel data were available only in this Mach number range. The total pressure and $\beta$ port readings from the flights are considered suspect because of leakage through the ports installed in the carbon-carbon composite leading edges. As a result, a $\beta$ estimation algorithm was not developed.

\section{VII. $\alpha$ Estimation}

The FADS $\alpha$ estimate was designed to be blended with the inertial $\alpha$ estimate to provide an air-mass-corrected value for use by the flight control laws. Since the algorithm was designed for use as an input to the flight control laws during the free-flight portion of the X-43A mission, a number of error checks and additional safeguards were added to the algorithm. The FADS $\alpha$ estimation algorithm was executed in real time throughout both the Mach 7 and Mach 10 missions, but was only used to aid the inertial solution during the period following the scramjet engine experiment of the Mach 7 mission. The FADS $\alpha$ estimation algorithm was not considered mature enough for use during the scramjet engine experiment. The FADS $\alpha$ estimation algorithms were not used to aid the inertial $\alpha$ estimate during the Mach 10 mission, because sufficient time was not available between the two missions to validate the algorithm for operation above Mach 8, analyze Mach 7 mission data, develop updates derived from the Mach 7 mission analysis, and implement changes to the flight software.

The FADS $\alpha$ estimation algorithms are discussed in detail in Ref. 1 . The PPT measurements used by the realtime algorithm were updated at $25 \mathrm{~Hz}$, and the algorithm was executed at $100 \mathrm{~Hz}$ as part of the flight control software. The FADS $\alpha$ estimate was derived from three independent $\alpha$ estimates, hereafter referred to as "FADS1," "FADS2," and "FADS3." The FADS1 estimate was derived from the differential pressure measurement between ports 2 and 4 . The FADS2 estimate was derived from the differential pressure measurement between ports 3 and 5. The final $\alpha$ estimate, FADS3, was derived from the difference between the absolute pressure measurements from ports 2 and 5 .

The FADS $\alpha$ estimates were calculated as shown in Eq. (1) where $\bar{q}$ represents dynamic pressure and $\mathrm{P}_{2}, \mathrm{P}_{3}$, $\mathrm{P}_{4}$, and $\mathrm{P}_{5}$ are the pressure readings at ports $2,3,4$, and 5, respectively. The differential pressure coefficients, $\mathrm{C}_{\mathrm{P} 24}, \mathrm{C}_{\mathrm{P} 35}$, and $\mathrm{C}_{\mathrm{P} 25}$, were scheduled as a function of Mach number and calculated from the FADS pressure port database, which consisted of pressure values for each port as a function of Mach number and $\alpha$.

$$
\begin{aligned}
& \text { FADS1 }=\left(\frac{\mathrm{P}_{2}-\mathrm{P}_{4}}{\overline{\mathrm{q}}}\right) C_{\mathrm{P} 24} \\
& \text { FADS2 }=\left(\frac{\mathrm{P}_{3}-\mathrm{P}_{5}}{\overline{\mathrm{q}}}\right) \mathrm{C}_{\mathrm{P} 35} \\
& \text { FADS3 }=\left(\frac{\mathrm{P}_{2}-\mathrm{P}_{5}}{\overline{\mathrm{q}}}\right) C_{\mathrm{P} 25}
\end{aligned}
$$

Figure 6 shows how the three individual FADS $\alpha$ estimates were combined with the inertial $\alpha$ measurement to generate the FADS $\alpha$ estimate for use by the flight control laws. The inertial $\alpha$ was passed through a Mach number-dependant lag model for each of the FADS $\alpha$ estimates. The lagged $\alpha$ values were subtracted from each of the three FADS $\alpha$ estimates, and these differences were evaluated to check the validity of the estimates. A FADS $\alpha$ estimate was considered valid if it was within a predetermined tolerance of the lagged inertial $\alpha$. The differences between the three FADS $\alpha$ estimates and the lagged inertial value were averaged over the valid FADS $\alpha$ estimates. This average was passed through a low pass filter, resulting in a low frequency bias term hereafter referred to as the "FADS bias," and was added to the inertial $\alpha$. The final result was the FADS $\alpha$ estimate, which had a low frequency component corrected by the FADS $\alpha$ algorithms, and a high frequency component from the inertial $\alpha$. If all three FADS $\alpha$ estimates were invalid, the value input to the low pass filter was set to zero, resulting in no correction to the inertial $\alpha$. 


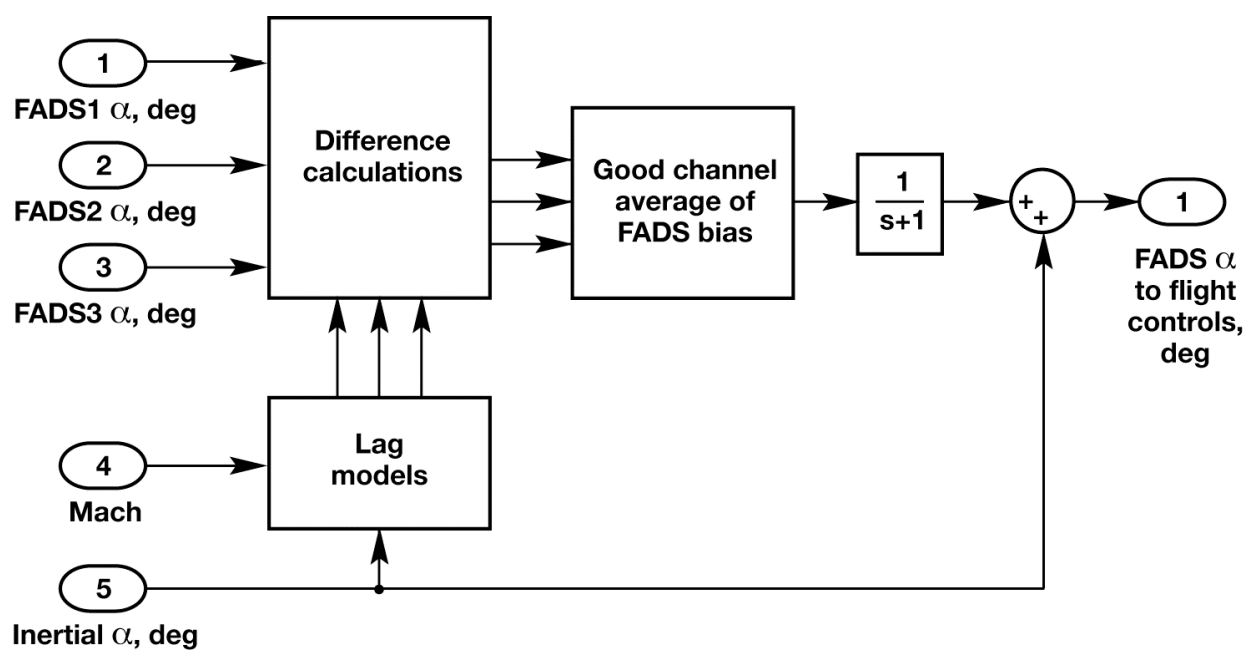

Figure 6. Complementary filter implementation.

A FADS pressure database, primarily derived from viscid and inviscid pressure predictions, was used to develop the FADS $\alpha$ estimation algorithms. The viscid and inviscid pressure values were generated by a series of FORTRAN routines, which computed the pressures on the upper and lower surfaces of the HXRV forebody surface ramps. The inviscid calculations utilize the oblique shock relations to model compressions while expansions were analyzed using the Prandtl-Meyer equations. Viscous interaction-induced pressures were estimated using the CHI-BAR correlations for flat plates in laminar flow. The FADS pressure database was developed for the Mach 2 to Mach 8 flight range. Above Mach 8, the database was linearly extrapolated to generate port pressure predictions. The viscid and inviscid theory predictions were considered most applicable at Mach 3 and above.

Wind tunnel data collected prior to flight were examined, but were used to update the FADS pressure database only in instances where the wind tunnel data compared well with theory. Wind tunnel data were collected at the following Mach numbers: 2, 2.25, 2.5, 2.75, 3, 4, 5, 6, and 8. Problems with the wind tunnel test hardware or data measurement system resulted in the data collected below Mach 3 being suspect. In addition, the wind tunnel data showed an unanticipated decrease in the pressure at the lower aft FADS port (port 5) as the Mach number decreased. This pressure decrease was most pronounced below Mach 5 where the difference between the wind tunnel results and theory increased with decreasing Mach number. The boundary layer trip strip located between ports 4 and 5 was examined and eliminated as a cause for the decreased pressure port reading. Wind tunnel tests, conducted as part of the FADS system development, were performed with boundary layer trip strips of varying sizes and compared to tests conducted without the trip strips. ${ }^{12}$ No significant differences were observed in the port 5 pressure port readings between the wind tunnel tests conducted with and without a boundary layer trip strip. The reason for the decreased lower aft pressure port reading, as compared to theory, is not understood. Prior to flight, this discrepancy in the port 5 pressure readings was thought to have been possibly caused by anomalies in either the FADS pneumatic system or wind tunnel test data acquisition system. The limited resources available prior to flight prevented a detailed analysis of the enigmatic lower aft port pressure reading and the corresponding incorporation of the wind tunnel test results into the FADS pressure database.

\section{Best Estimated Trajectory}

A best estimated trajectory (BET) was developed for both the Mach 7 mission ${ }^{13}$ and the Mach 10 mission. ${ }^{14}$ The BET was generated from in-flight telemetry data, which was combined with various redundant measurements, to generate maximum-likelihood estimates of the vehicle position, velocity, and orientation time histories along with estimates of their uncertainties. These results were then combined with an independent atmosphere reconstruction, which included uncertainties, to yield wind-relative parameters that are required for detailed analysis of the vehicle performance during flight conditions. The independent atmosphere reconstruction used balloon data from various locations on and around the test range. Atmospheric and wind data along the actual flight path of the X-43A were not available, so the BET data has increasing uncertainty as the missions progress. The BET data referred to in this paper are provided from the BET reconstruction efforts.

American Institute of Aeronautics and Astronautics 


\section{Mach 7 Mission and Mach 10 Mission Comparisons}

Figure 7 compares the BET $\alpha$ during the ascent and descent portions of the two missions as a function of the BET Mach number. All figures displaying data from the ascent portion of the missions are plotted against increasing Mach number, which is consistent with plotting as a function of increasing time. Correspondingly, the data from the descent portion of the mission is plotted against decreasing Mach number. Figure 8 compares the BET $\overline{\mathrm{q}}$ during the ascent and descent portions of the two missions. As shown in Figs. 7 and 8, the X-43A flew at different $\alpha$ and $\bar{q}$ profiles during the two flights. As a result, direct comparisons of FADS data between the two missions are not possible. The Reynolds number during the ascent and descent portions of the flights is similar between the two missions. In general, the ascent portion of the missions experienced a higher Reynolds number than during the descent portion.

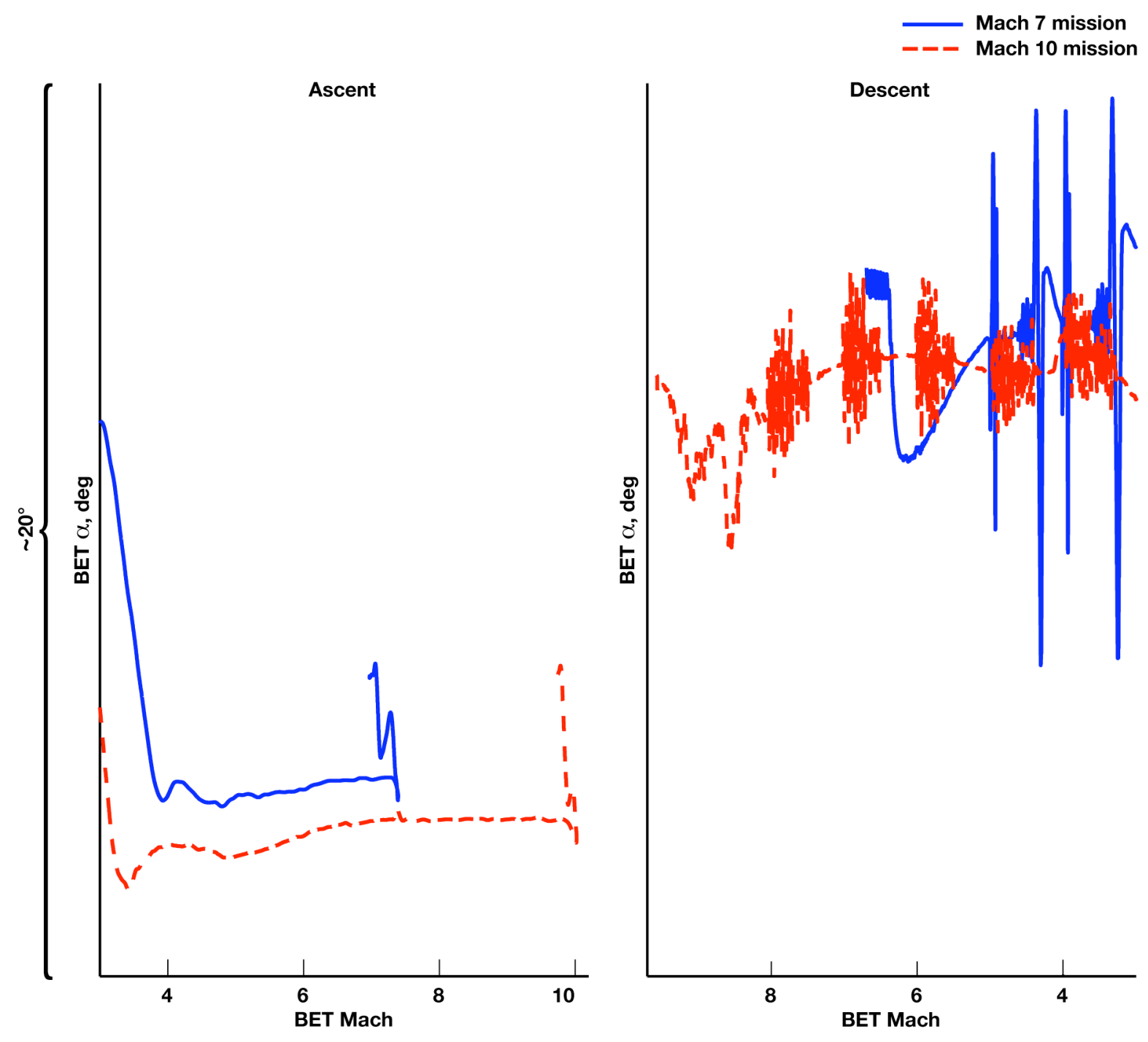

Figure 7. BET $\alpha$ comparison between the Mach 7 and Mach 10 missions. 


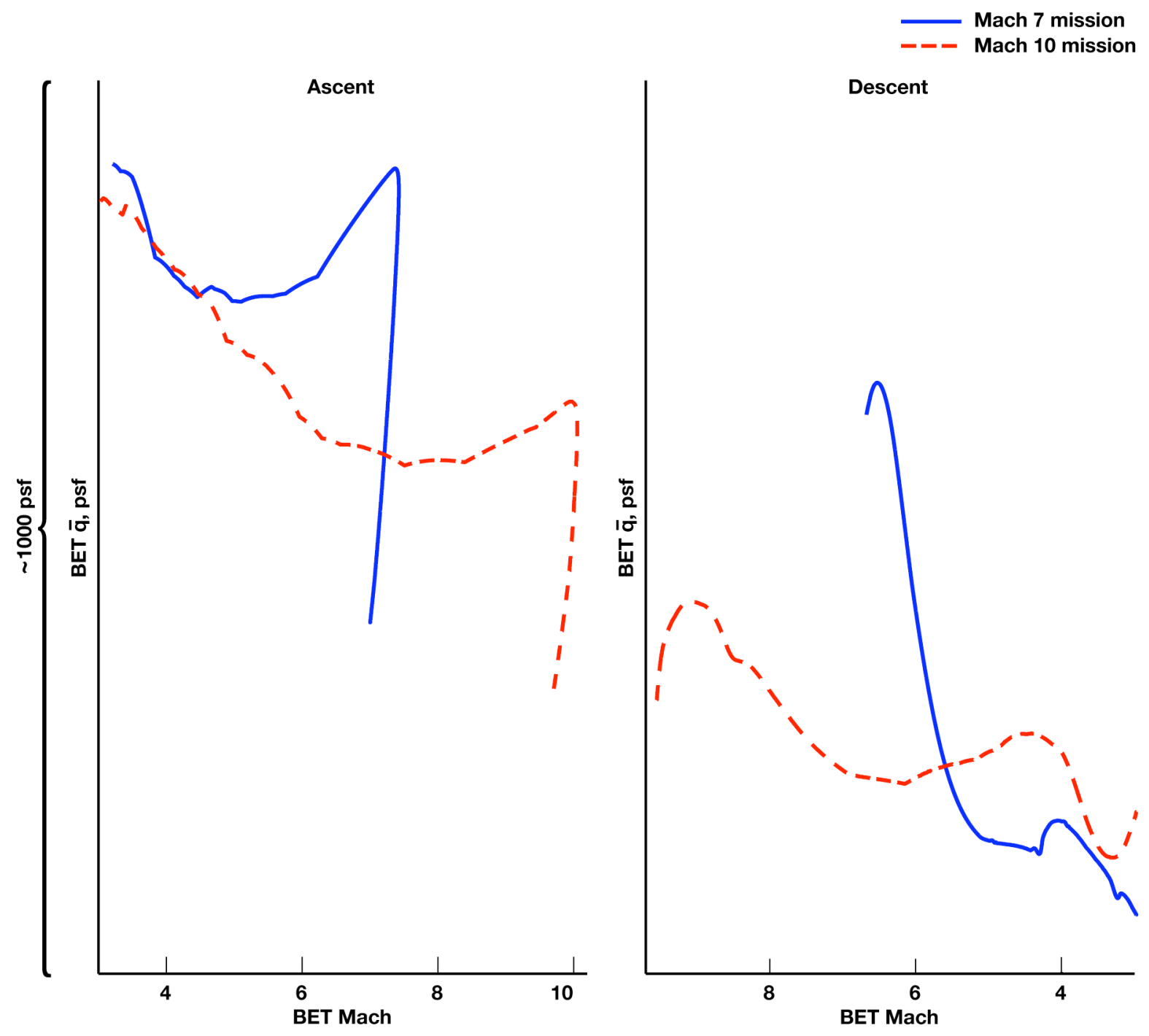

Figure 8. BET $\bar{q}$ comparison between the Mach 7 and Mach 10 missions.

\section{Mach 7 Mission Flight Test Results}

The FADS $\alpha$ estimation algorithms were intended to provide an input to the X-43A flight control laws during the free-flight portion of the mission, which includes the descent portion following the scramjet engine test. Although the algorithms performed well during the ascent portion, they are discussed in detail only for the descent portion of the missions, which is the designed operating region. Figure 9 compares the FADS $\alpha$ estimate for the Mach 7 mission with the onboard inertial and BET values. Figure 9 also shows the differences between the FADS $\alpha$ estimate and the inertial and BET values and includes the algorithm's bounds for determining FADS $\alpha$ estimate validity. During dynamic maneuvers such as the PID maneuvers, greater differences are seen between the FADS $\alpha$ estimate, BET $\alpha$, and inertial $\alpha$ because the FADS $\alpha$ estimate lags the BET and inertial $\alpha$ values. Throughout the Mach 7 mission, the BET and onboard inertial $\alpha$ values are similar. The FADS $\alpha$ estimate remains within $1^{\circ}$ of the inertial and BET values throughout most of the descent portion of the Mach 7 mission. At the higher Mach number, the FADS $\alpha$ estimate is within a few tenths of a degree of the inertial and BET values until drifting from the BET and inertial values during the Mach 5 PID maneuver. Following the Mach 3 PID maneuver, the difference between the FADS $\alpha$ estimate and the inertial $\alpha$ was outside of the allowable bounds, and the FADS $\alpha$ estimate was declared invalid. At this point, the FADS $\alpha$ estimate was set to the inertial value, which explains why the difference between the two is zero after this point. The FADS valid bounds decrease following the Mach 3 PID maneuver as a means of intentionally failing the FADS $\alpha$ estimate as the Mach number decreased to a point beyond 
which the FADS pressure predictions were considered invalid. During the Mach 3 PID maneuver, the FADS $\alpha$ estimate begins to track the inertial and BET values better for a short period of time. The reason for this better performance is that the FADS2 and FADS3 estimates are determined to be invalid, and FADS1 was used exclusively to calculate the FADS $\alpha$ estimate. Figure 10 shows the point at which FADS2 and FADS 3 exceed their individual tolerances and are determined to be invalid.

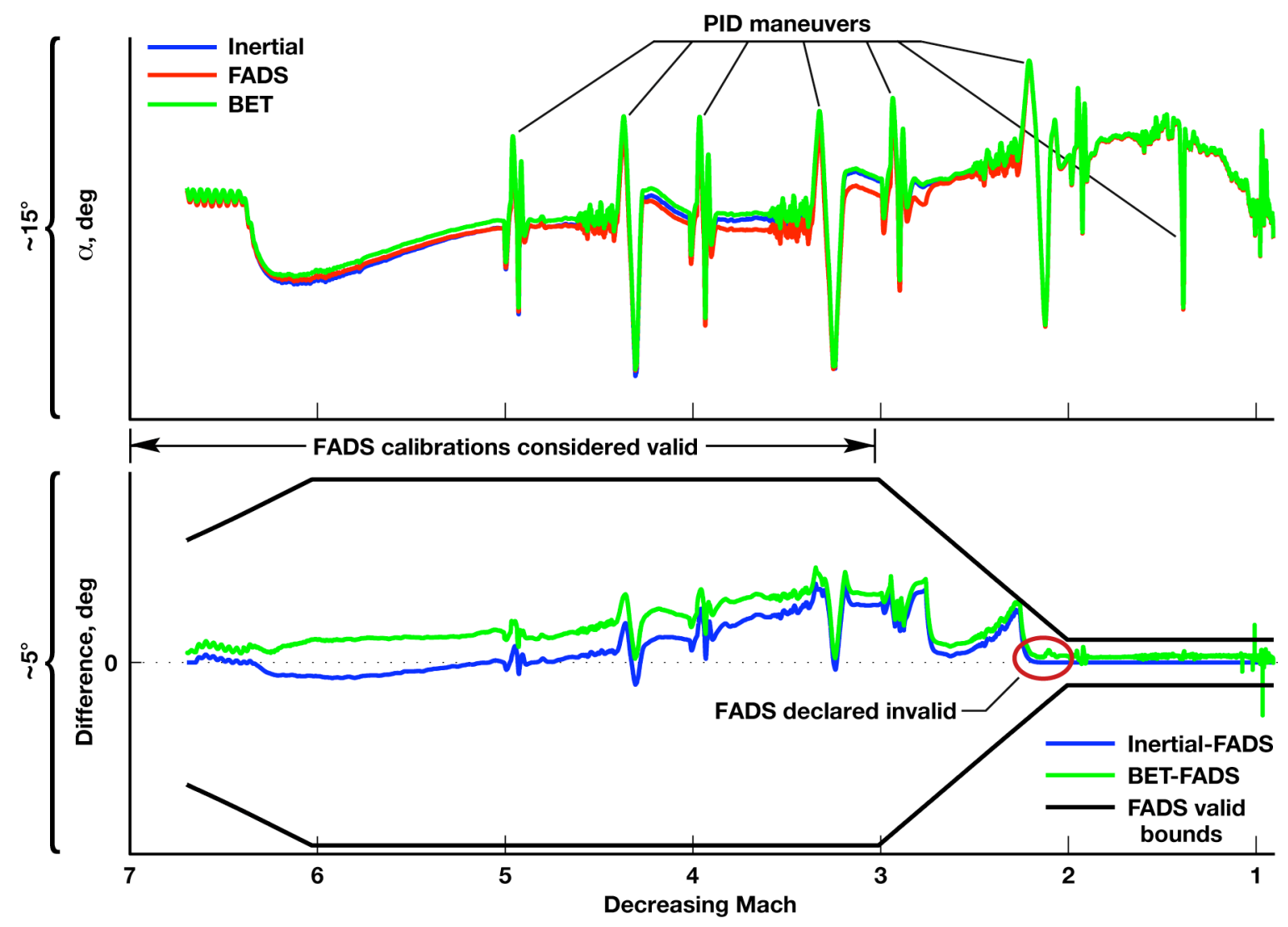

Figure 9. Inertial, FADS, and BET $\alpha$ comparisons for the Mach 7 mission. 

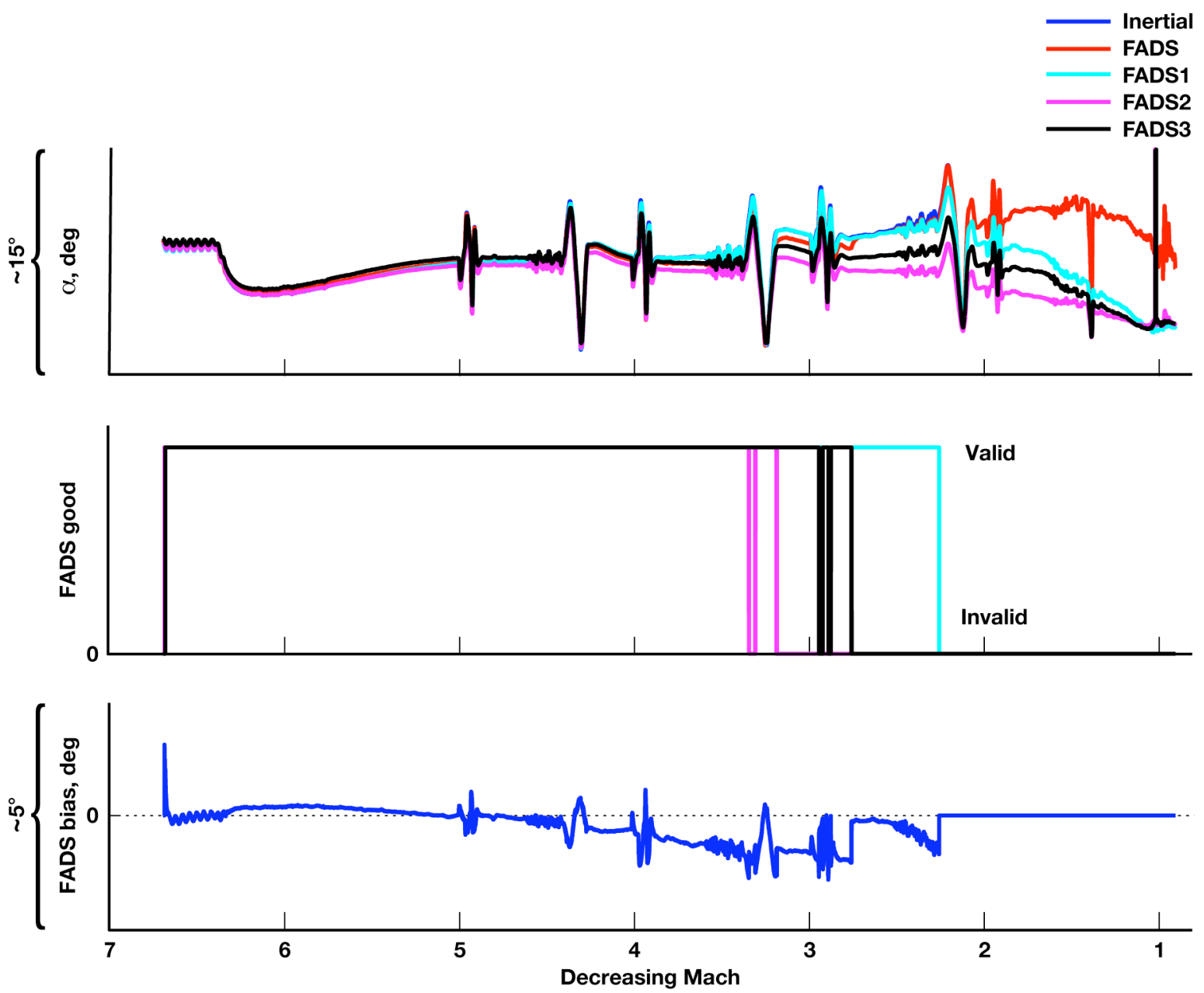

Figure 10. Separate FADS $\alpha$ estimates and FADS bias for the Mach 7 mission.

Figure 10 shows the inertial $\alpha$ estimate (blue line) compared to the FADS $\alpha$ estimate (red line) and the three separate $\alpha$ estimates used to determine the FADS $\alpha$ estimate. The inertial and FADS $\alpha$ estimate values are very similar throughout the descent portion. After all of the FADS $\alpha$ estimates are considered invalid, the FADS $\alpha$ estimate is set to the inertial $\alpha$ value. Also shown in Fig. 10 are the FADS flags used to determine the validity of the three separate estimates, and the FADS bias that is applied to the inertial $\alpha$ to compute the FADS $\alpha$ estimate. The FADS1 $\alpha$ estimate, which uses the two forward ports (ports 2 and 4), tracks the inertial $\alpha$ better than the FADS2 and FADS3 estimates, both of which rely on port 5. The FADS1 $\alpha$ estimate is considered valid until nearly the end of the Mach 3 PID maneuver, while the FADS2 and FADS3 $\alpha$ estimates had drifted enough from the inertial value to be considered invalid around Mach 3. The FADS2 and FADS3 $\alpha$ estimates drift away from the inertial and BET $\alpha$ values during the Mach 5 PID maneuver due to the port 5 pressure reading being lower than predicted by the FADS pressure database, which was used to generate the algorithms. 
To capture the pressure lag effects, the inertial $\alpha$ value is passed through a lag model in the FADS $\alpha$ estimation algorithm before being compared to each FADS $\alpha$ estimate. The lag models for each FADS $\alpha$ estimate were determined from wind tunnel data. Figure 11 compares the inertial and lagged inertial values and FADS1 $\alpha$ estimate during the Mach 5 PID maneuver. The differences between the FADS1 $\alpha$ estimate and the inertial and lagged inertial values are also shown. The FADS1 $\alpha$ estimate tracks the lagged inertial value well, which indicates a good lag model. Results for the other two FADS $\alpha$ estimates are similar.
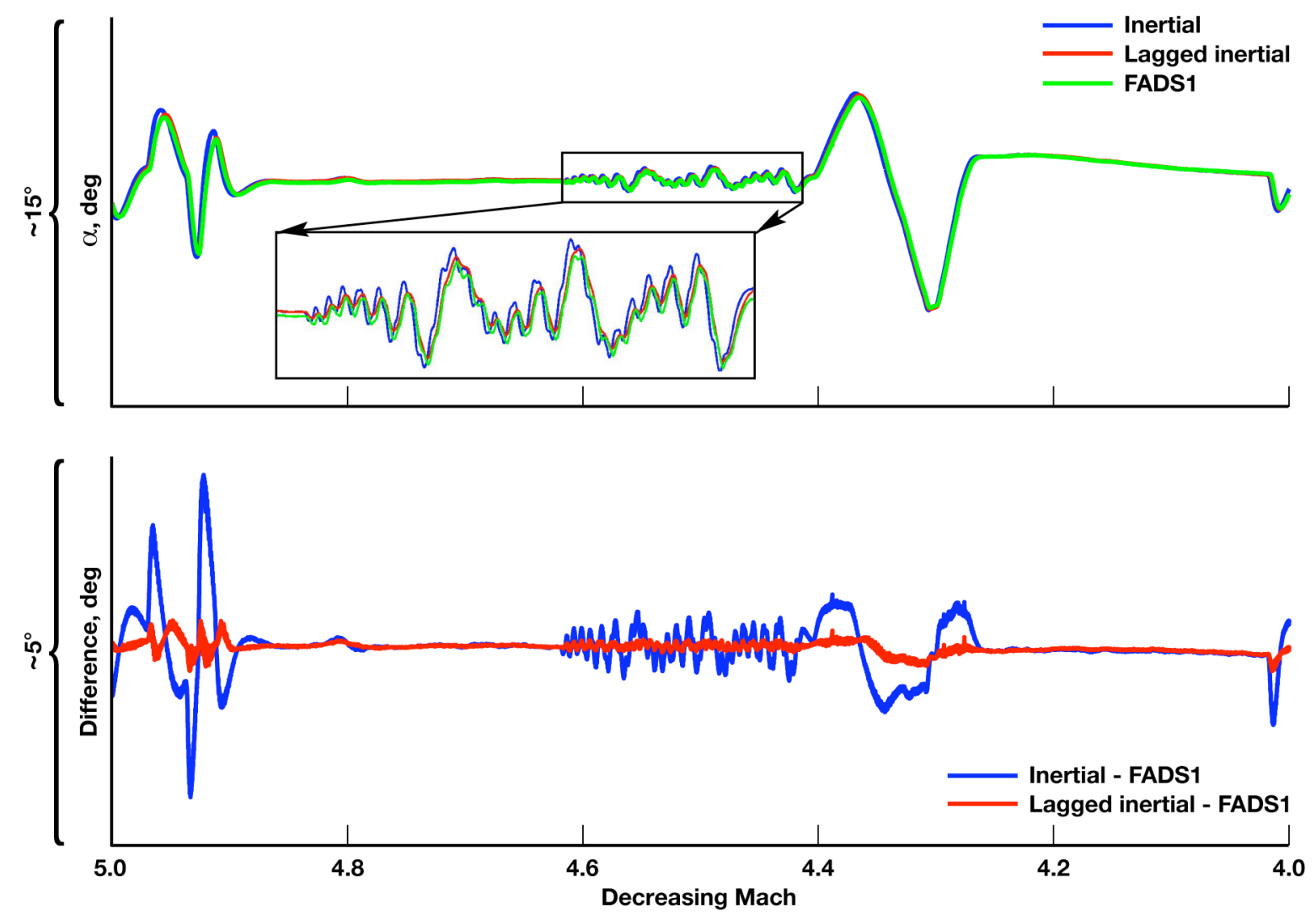

Figure 11. FADS1 $\alpha$ estimate compared to inertial and lagged inertial $\alpha$ values for the Mach 7 mission during a portion of the Mach 5 PID maneuver. 


\section{Mach 10 Mission Flight Test Results}

The FADS $\alpha$ estimation algorithm performance during the Mach 10 mission was similar to that of the Mach 7 mission. Figure 12 compares the FADS $\alpha$ estimate during the Mach 10 mission with the onboard inertial and BET values. The BET and onboard inertial $\alpha$ values are similar during the Mach 10 mission. Above Mach 8, the FADS $\alpha$ estimate tracks the inertial and BET values to within $0.5^{\circ}$, even though the algorithm was not designed to operate at these higher Mach numbers. The FADS $\alpha$ estimate begins to drift from the BET and inertial values during the Mach 5 PID. Following the Mach 3 PID maneuver, the FADS $\alpha$ estimate differs enough from the onboard inertial value, such that the error between the two is outside of the allowable bounds. As in the Mach 7 mission, the FADS $\alpha$ estimate begins to track the inertial and BET values better at some point during the Mach 3 PID maneuver as the FADS2 and FADS3 $\alpha$ estimates are declared invalid.

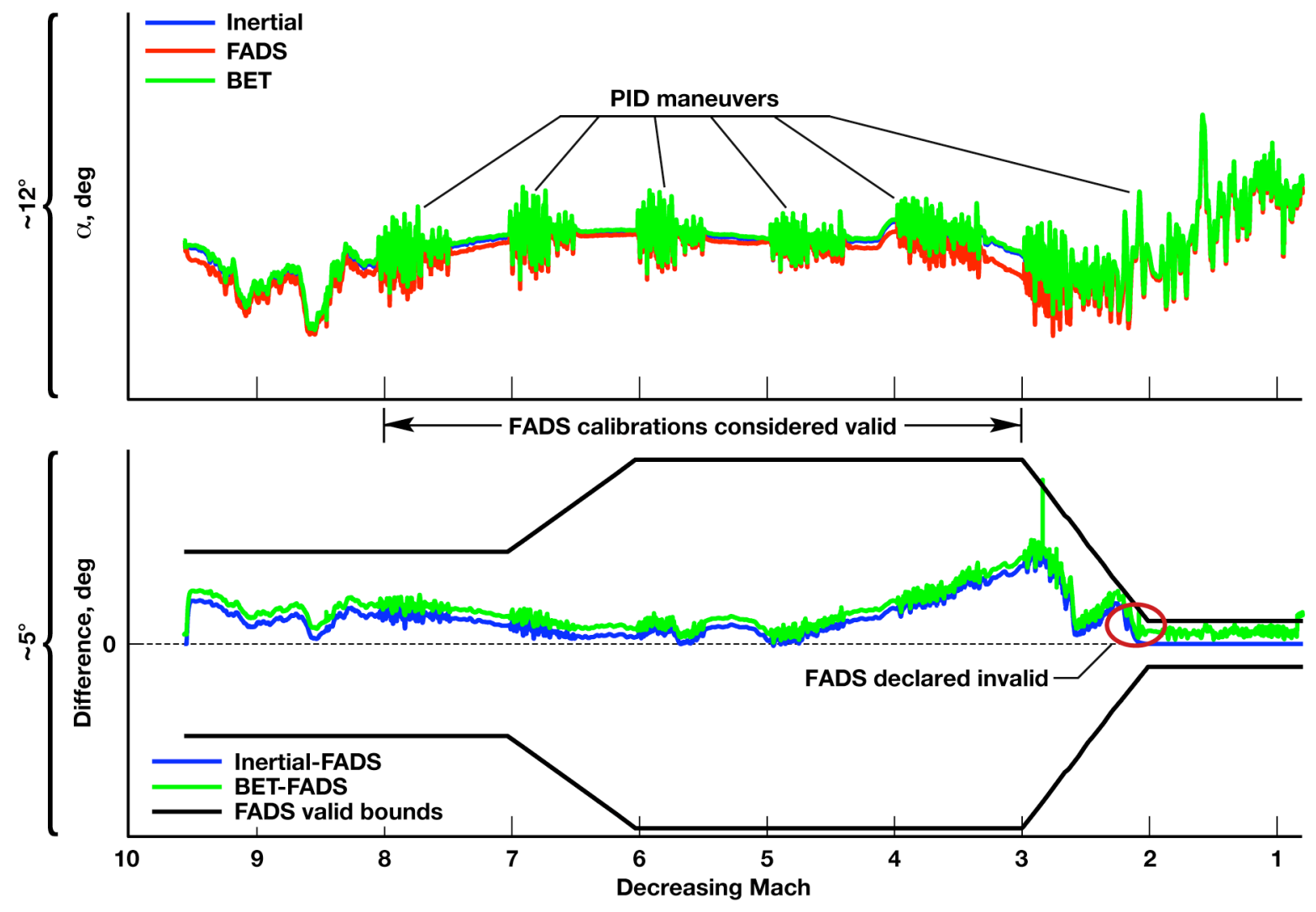

Figure 12. Inertial, FADS, and BET $\alpha$ comparisons for the Mach 10 mission. 
Figure 13 shows the inertial $\alpha$ estimate (blue line) compared to the FADS $\alpha$ estimate (red line) and the three separate $\alpha$ estimates used to determine the FADS estimate. Also shown in Fig. 13 is the FADS bias applied to the inertial $\alpha$ along with the flag used to determine the validity of the three separate estimates. The FADS1 $\alpha$ estimate, which uses the two forward ports, tracks the inertial $\alpha$ better than the FADS2 and FADS3 $\alpha$ estimates, both of which rely on port 5. The FADS1 $\alpha$ estimate is considered valid until nearly the end of the Mach 3 PID maneuver, while the FADS2 and FADS3 $\alpha$ estimates have drifted enough off from the inertial value to be considered invalid slightly after the start of the Mach 3 PID maneuver. As in the Mach 7 mission, the FADS2 and FADS $3 \alpha$ estimates drift away from the inertial and BET $\alpha$ values during the Mach 5 PID maneuver.
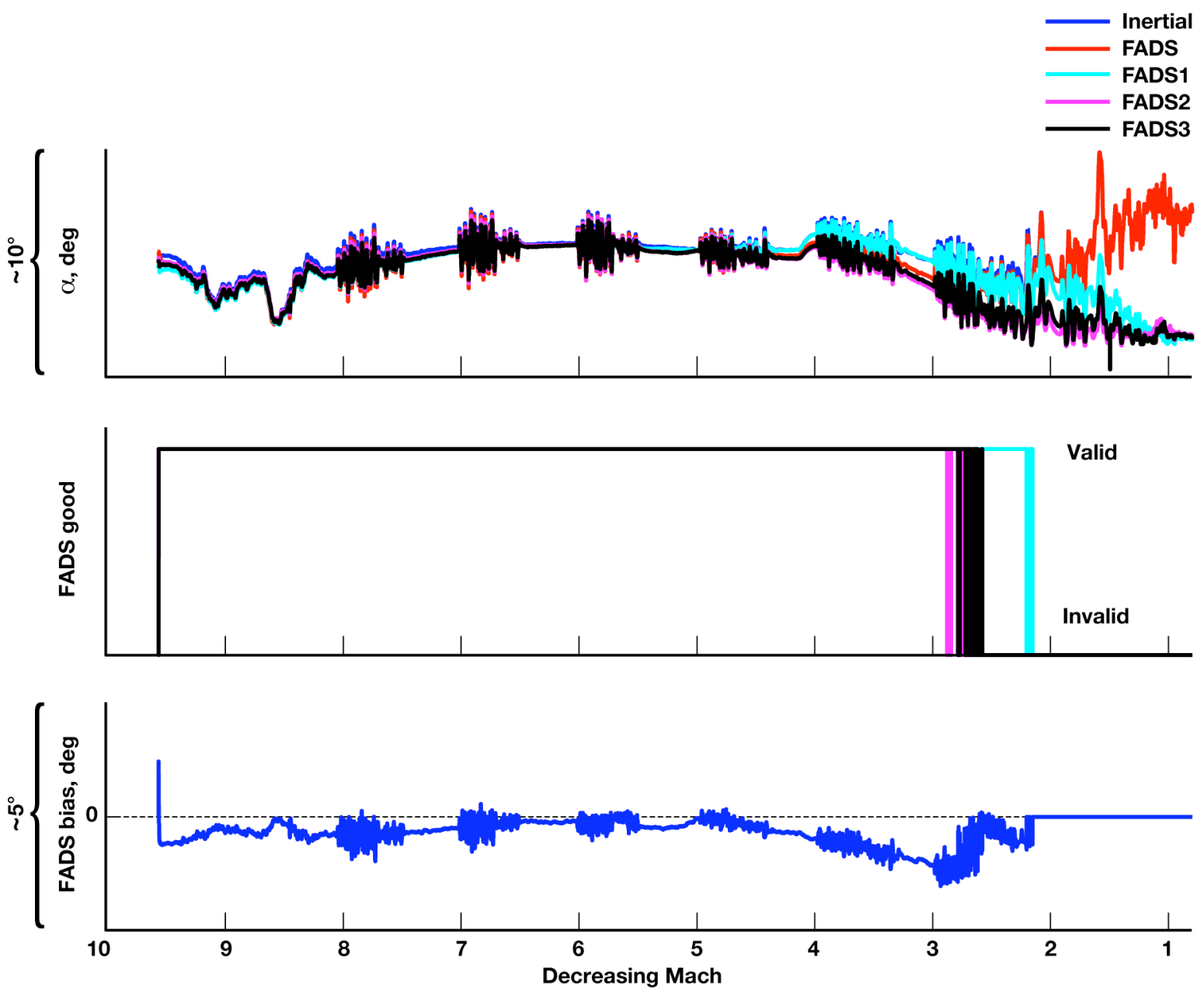

Figure 13. Separate FADS $\alpha$ estimates and FADS bias for the Mach 10 mission.

The lag models in the FADS $\alpha$ estimation algorithm show similar performance during the Mach 10 mission as that of the Mach 7 mission. Since the lag model performance between the two missions is similar, the actual performance during the Mach 10 mission is not presented.

The real-time FADS $\alpha$ estimation algorithm performed well during the two missions. This performance demonstrates the feasibility of this approach for generating an air-mass-corrected $\alpha$ estimate for a sharp-nosed hypersonic vehicle.

\section{FADS Pressure Port Comparisons}

During the detailed post-flight examination of the results from the Mach 7 and Mach 10 missions, the pressure readings for the lower aft port (port 5) were observed to be noticeably lower than those in the FADS pressure port database, and the difference increased with decreasing Mach number. The data from both missions shows the same trend for port 5 as that observed in the wind tunnel. Currently, an explanation is not available for the lower pressure 
measured at port 5 in the wind tunnel and during the two flights. The fact that the same trend is present in the wind tunnel tests, the Mach 7 mission, and the Mach 10 mission is necessary but not sufficient evidence that this trend is a real phenomenon. Ongoing research is being conducted to investigate the reason for the decreased pressure reading in port 5. Areas of continuing work include conducting two- and three-dimensional computational fluid dynamics (CFD) analyses and continued examination of the wind tunnel and flight test data.

Following the observation that the wind tunnel and flight data for port 5 exhibit similar trends, a new FADS pressure port database, hereafter referred to as the "new database," was generated that utilized the wind tunnel data for ports $2-5$ at Mach 2.5, 3, 4, 5, 6, and 8. The original FADS pressure port database, which was used to generate the algorithm calibrations used in flight, was based primarily on theory, and is hereafter referred to as the "original database."

Only one wind tunnel run at each Mach number was used to generate the new database, and the wind tunnel data were adjusted prior to incorporation in the new database. The differential PPT data from the wind tunnel test should read zero at a specific $\alpha$ determined from the forebody geometry. Additionally, the ratio of the absolute PPT reading and total pressure should be equal to one when the forebody is at an $\alpha$ equal to the ramp angle of the upper or lower surface. Biases to the PPT measurements were determined such that these criteria were met. These biases were then applied to the wind tunnel data to generate the new database. The magnitude of the biases is relatively small, generally between 0.1 to $2.0 \mathrm{psf}$, and is similar to the PPT measurement accuracy.

Figure 14 displays the pressure port comparisons between the original database, the raw wind tunnel data, and the new database at Mach 8. Good agreement exists between the original and the new databases at Mach 8. The same pressure port comparisons at Mach 3 are shown in Fig. 15. At Mach 3, the two databases predict similar pressures for the forward ports. Differences are observed in port 3, as the new database predicts higher pressures than the original database as $\alpha$ increases, and lower pressures at negative $\alpha$. The greatest differences between the original and new databases for port 3 are on the order of 10 psf. The port 5 pressures from the new and original databases are as much as 50 psf different at the highest $\alpha$. 

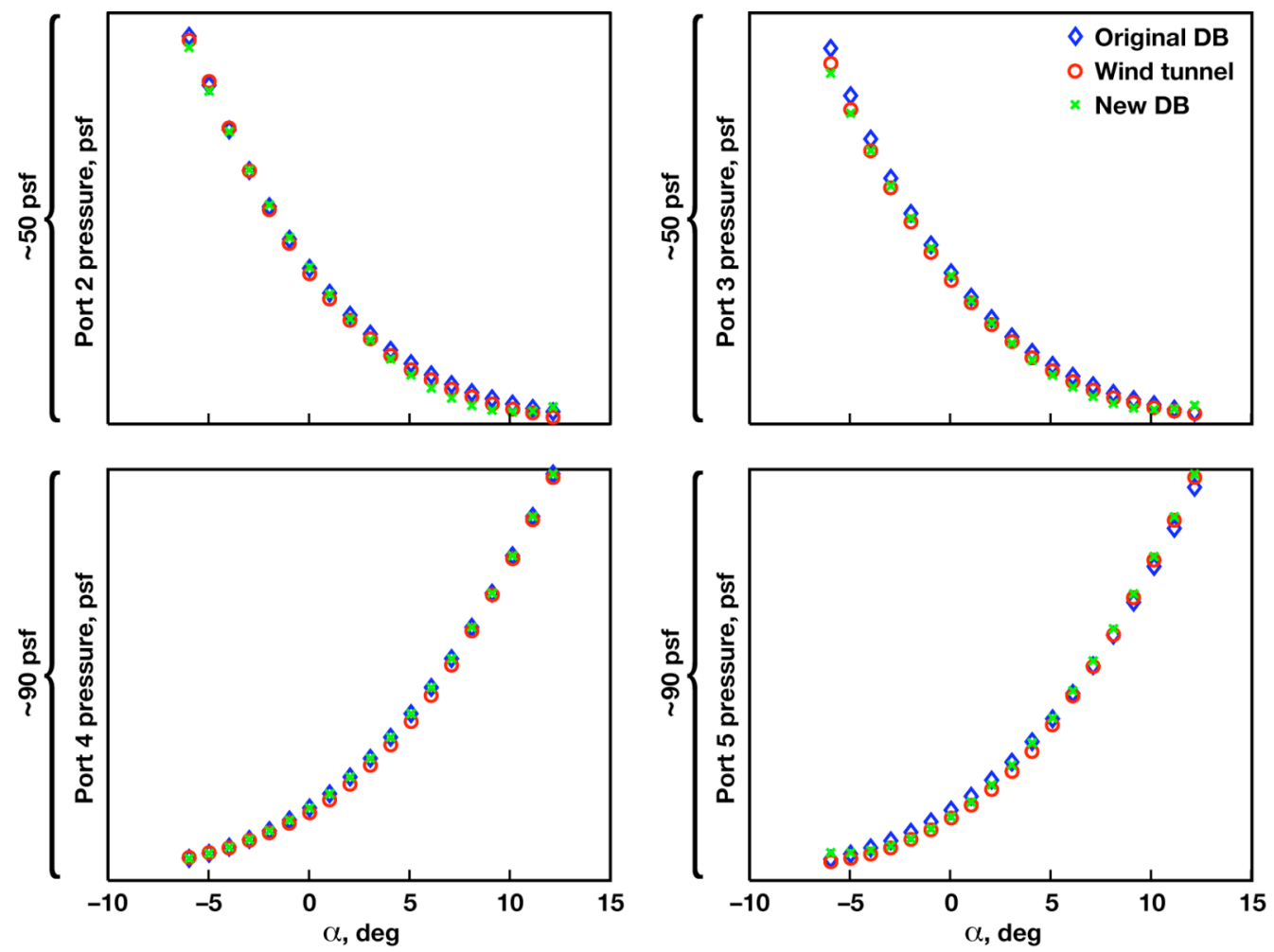

Figure 14. Mach 8 pressure port predictions.
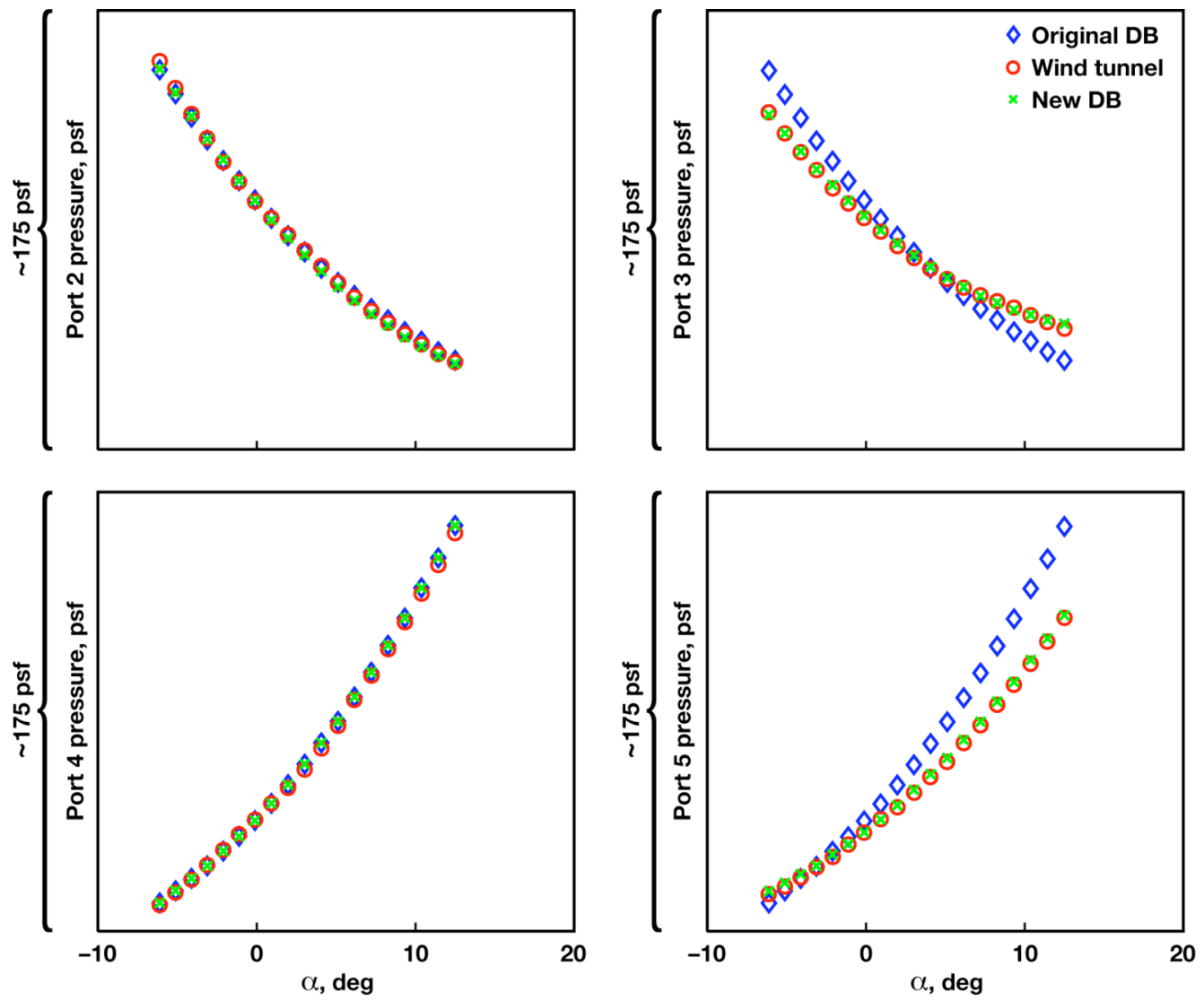

Figure 15. Mach 3 pressure port predictions.

18

American Institute of Aeronautics and Astronautics 
Figure 16 shows the forward pressure ports (ports 2 and 4) readings during the ascent portion of the Mach 7 mission. The flight data is compared to the original and new database predictions. The new and original databases yield similar predictions for the forward ports. The port 2 predictions are within $15 \mathrm{psf}$ of the flight values with the greatest difference occurring around Mach 7. The port 4 predictions are within $7 \mathrm{psf}$ of the flight values.

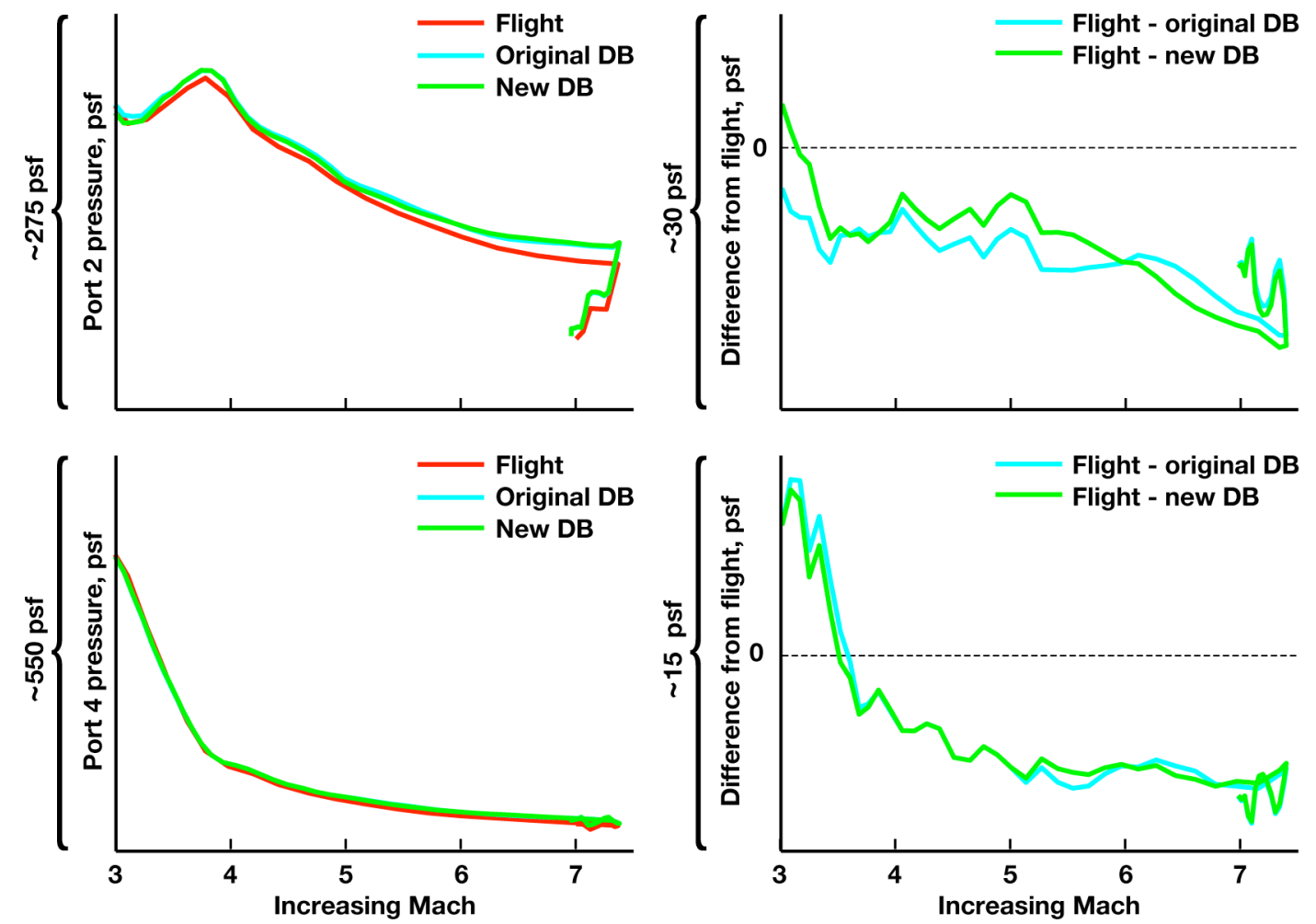

Figure 16. Forward pressure port readings during the Mach 7 mission ascent.

The aft pressure port readings from the ascent portion of the Mach 7 mission are compared to the new and original database predictions as shown in Fig. 17. The new database matches the flight pressure readings significantly better, particularly at the lower Mach numbers. The prediction from the new database is within $10 \mathrm{psf}$ of the flight data for port 3 and within 5 psf of the flight data for port 5 .

Figure 18 shows the forward pressure port readings from the descent portion of the Mach 7 mission compared to the new and original databases. The flight data compares well with both databases. The new database tracks the flight readings for port 2 to within 3 psf, which is slightly better than the original database. Predictions from the new and original databases indicate a bias of approximately $15 \mathrm{psf}$ from the flight readings for port 4. The FADS1 $\alpha$ estimate uses the differential pressure between the two forward ports, and had the best performance of the three FADS $\alpha$ estimates. This performance was realized from the good comparisons between the flight data and database predictions for the two forward pressure ports. 

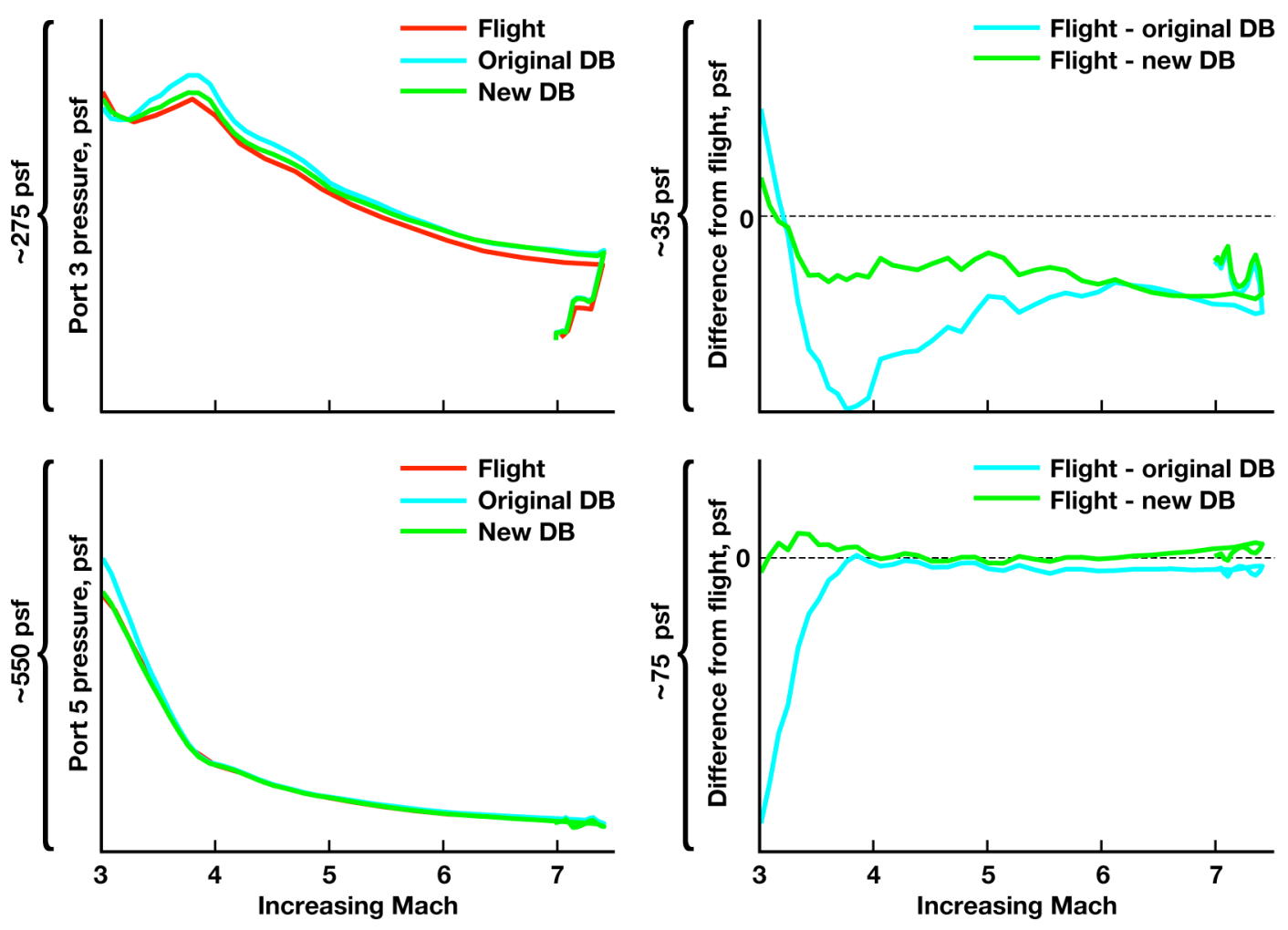

Figure 17. Aft pressure port readings during the Mach 7 mission ascent.
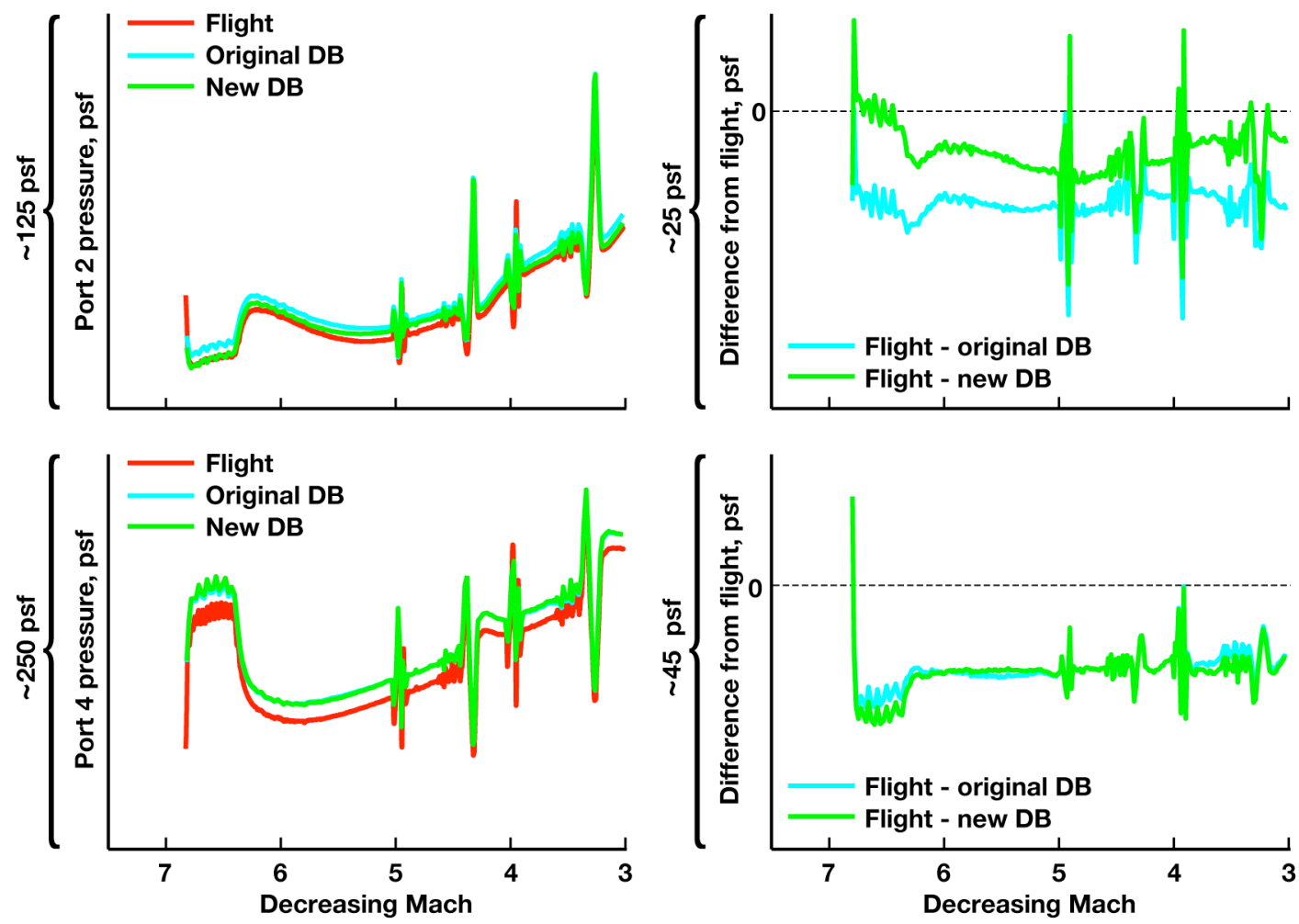

Figure 18. Forward pressure port readings during the Mach 7 mission descent. 
Figure 19 shows the aft pressure port comparisons during the descent portion of the Mach 7 mission. The new database predictions compare well with the flight readings. The original database exhibits an increasing pressure difference for port 5 as the Mach number decreases. This increasing difference is reflected in the FADS2 and FADS3 $\alpha$ estimates (Fig. 10), which rely on the port 5 pressure. The mismatch in pressure between the original database and flight caused the FADS2 and FADS3 $\alpha$ estimates to drift. The new database predictions for port 5 are biased approximately $5 \mathrm{psf}$ higher than the flight readings. The new database also provided better matching of the port 3 flight data below Mach 5.
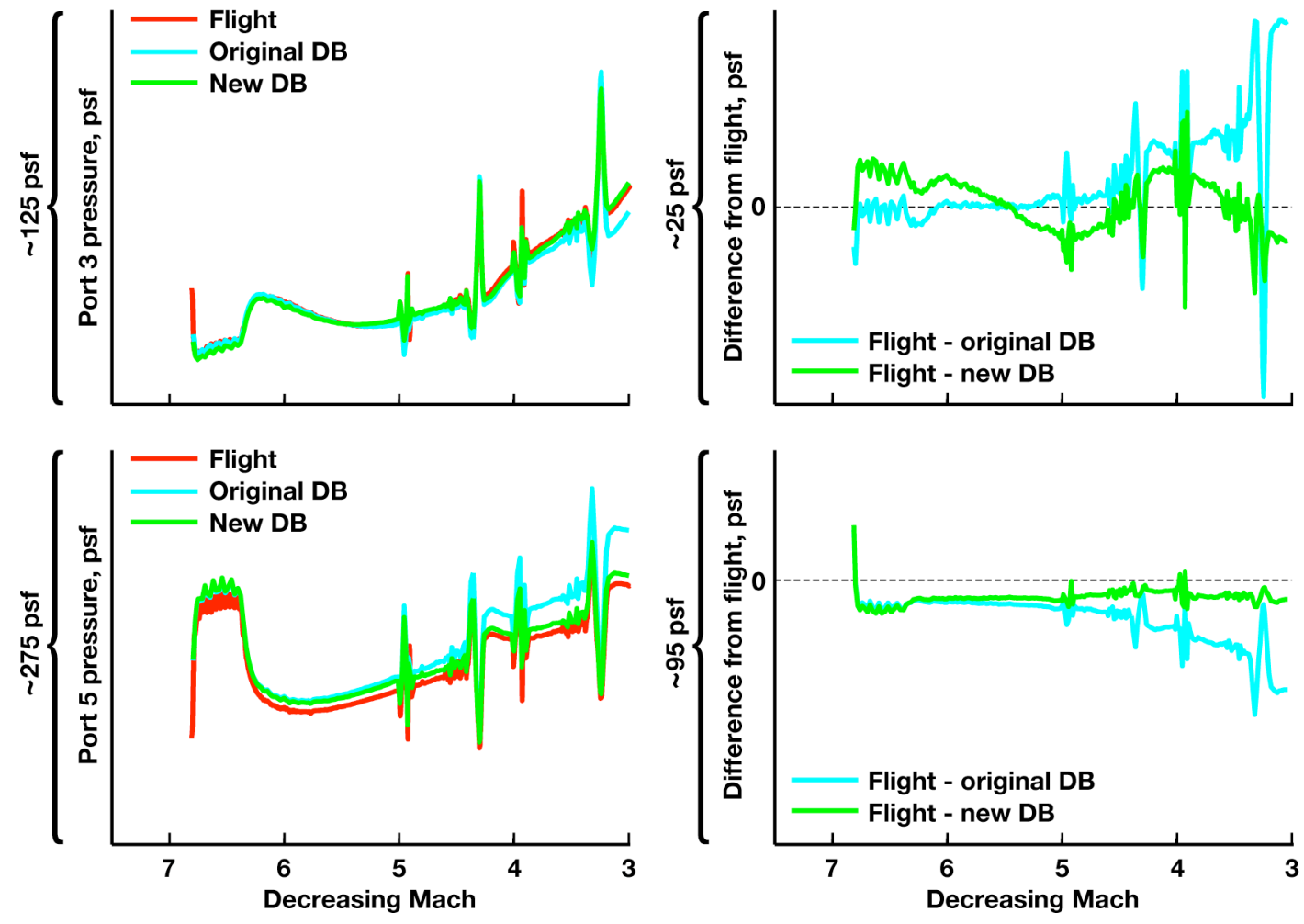

Figure 19. Aft pressure port readings during the Mach 7 mission descent.

The Mach 10 mission pressure comparisons are similar to those of the Mach 7 mission. Figure 20 shows the aft pressure port comparisons for the descent portion of the Mach 10 mission. The new database predictions for port 3 compare slightly better than those of the original database above Mach 5. Similar to the Mach 7 mission comparisons, the new database predictions for port 5 match the flight pressure readings of the Mach 10 mission significantly better than the original database.

Updated calibrations were generated for the FADS $\alpha$ estimation algorithm from the new database. Flight data from the ascent and descent portions of each mission was run through the real-time flight algorithms to generate FADS $\alpha$ estimates with the calibrations derived from the new database. The FADS $\alpha$ estimates generated with the original database are hereafter referred to as the "original $\alpha$ estimates," while the estimates generated with the new database are hereafter referred to as the "new $\alpha$ estimates."

The FADS $\alpha$ estimates during the ascent portion of the Mach 7 mission are compared to the inertial and BET values as shown in Fig. 21. Below Mach 5.5, the new $\alpha$ estimate tracks the inertial and BET $\alpha$ values better than the original $\alpha$ estimate. Above approximately Mach 5.5, the new $\alpha$ estimate performs slightly worse than the original $\alpha$ estimate. The new $\alpha$ estimate is within $0.5^{\circ}$ of the inertial and BET $\alpha$ values throughout the ascent portion of the mission. Figure 22 compares the inertial and BET $\alpha$ values from the descent portion of the Mach 7 mission to the original and new $\alpha$ estimates. The new $\alpha$ estimate tracks the BET and inertial $\alpha$ values to within $0.5^{\circ}$, which is significantly better than the original $\alpha$ estimate below Mach 5. Above approximately Mach 6 , the original $\alpha$ estimates provide slightly better tracking of the inertial and BET $\alpha$ values. 

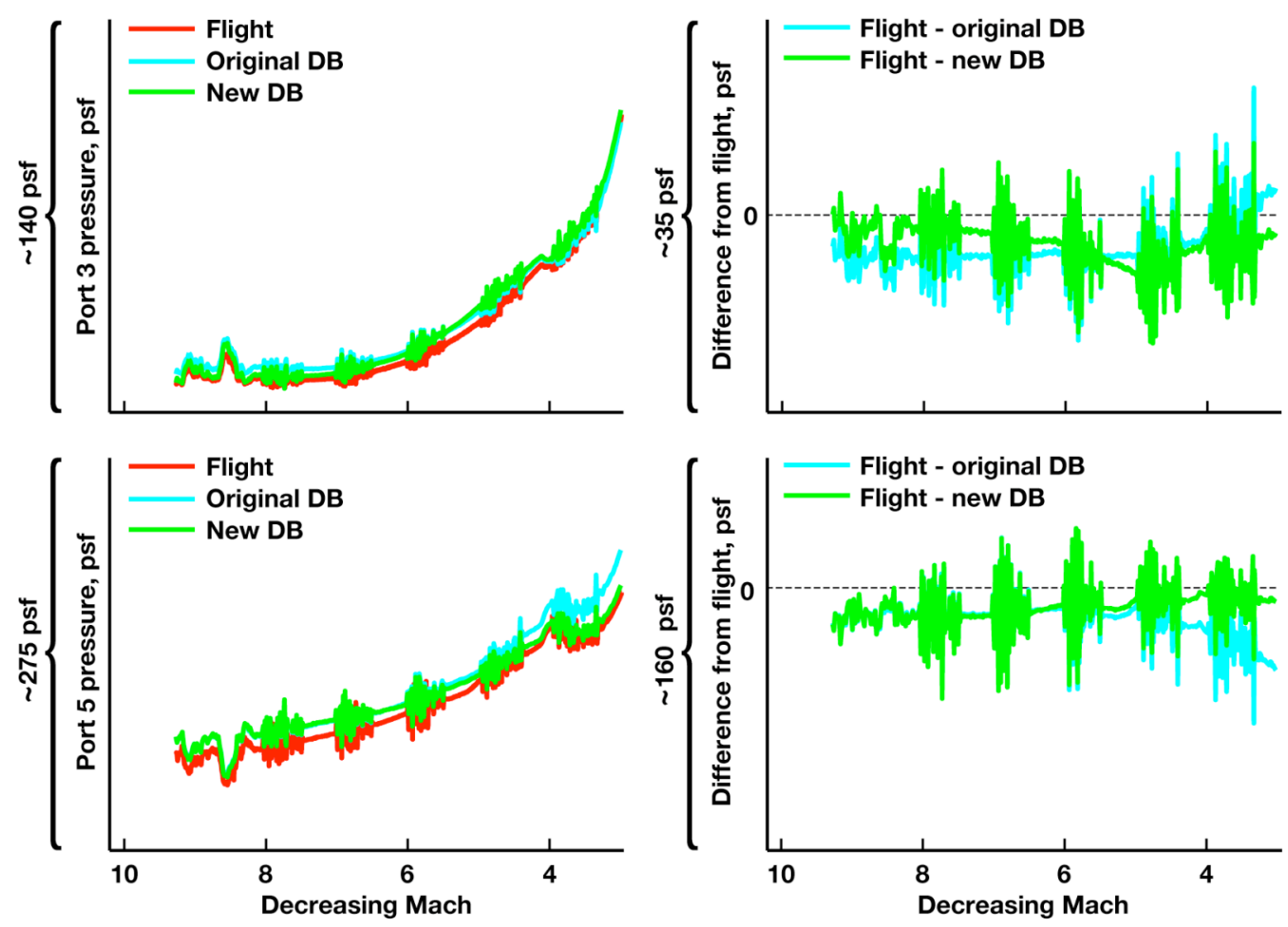

Figure 20. Aft pressure port readings during the Mach 10 mission descent.
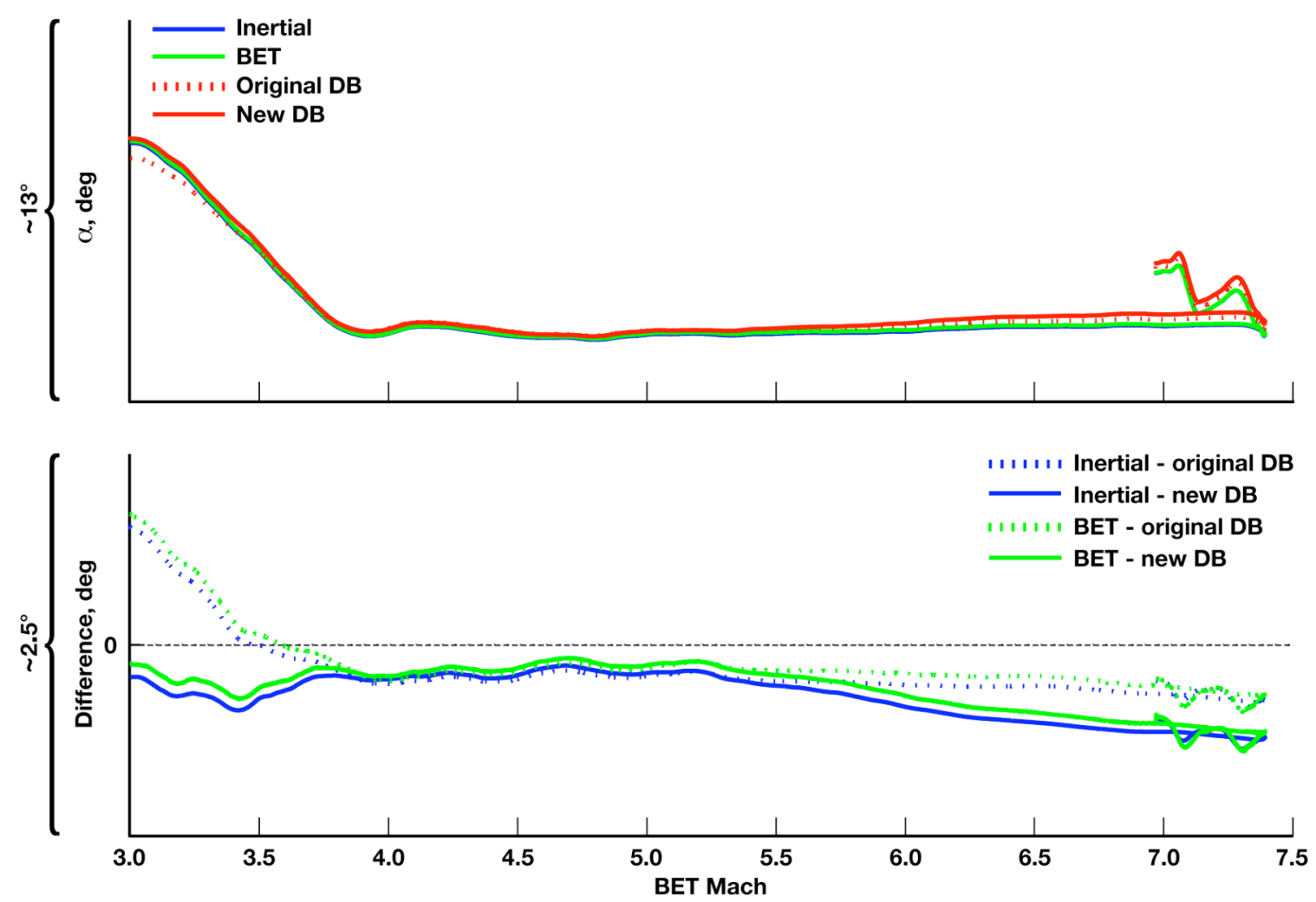

Figure 21. FADS $\alpha$ comparisons using the new and original databases for the Mach 7 mission ascent. 

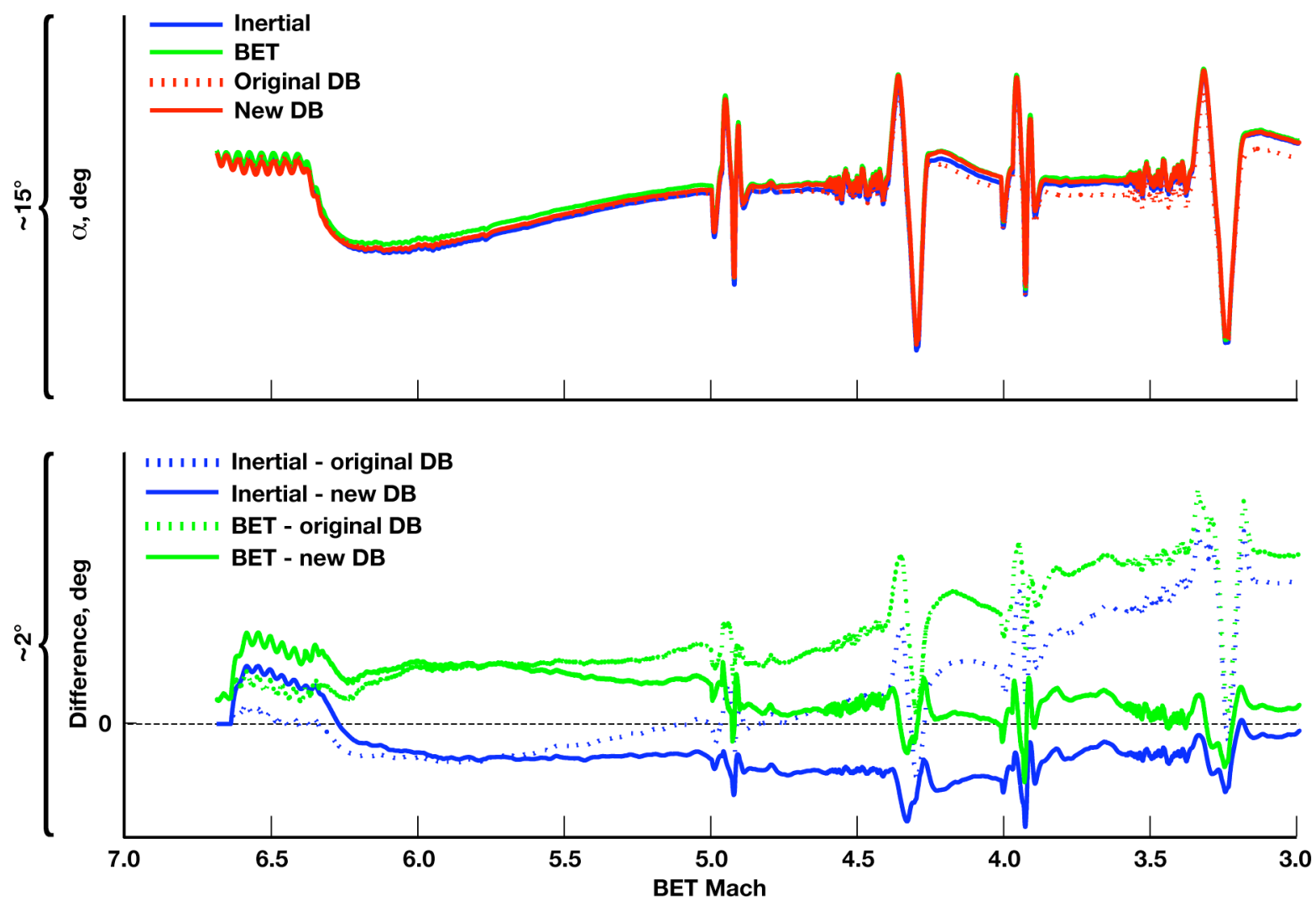

Figure 22. FADS $\alpha$ comparisons using the new and original databases for the Mach 7 mission descent.

Figure 23 shows the original and new $\alpha$ estimates compared to the inertial and BET values for the ascent portion of the Mach 10 mission. Similar to the Mach 7 mission, the new $\alpha$ estimates perform better than the original estimates until approximately Mach 6 . Above this point, the new $\alpha$ estimates are slightly worse; the difference between the new and original $\alpha$ estimates is on the order of $0.2^{\circ}$. The same trend is shown in Fig. 24, which displays the $\alpha$ estimates, inertial $\alpha$, and BET $\alpha$ during the descent portion of the Mach 10 mission. The new $\alpha$ estimates perform slightly worse than the original $\alpha$ estimate above approximately Mach 6 , and perform significantly better below this point. The new $\alpha$ estimate is within $0.8^{\circ}$ of the inertial and BET values at the higher Mach numbers, and even closer at the lower Mach numbers.

The wind tunnel data incorporated into the new database results in the updated FADS $\alpha$ estimation algorithm matching the flight results significantly better below Mach 6. Above Mach 6, the updated algorithm performs slightly worse than the original FADS $\alpha$ estimation algorithm. This slight degradation in performance is due to the incorporation of the Mach 8 wind tunnel data into the new database, and indicates that data at this point requires further examination. 

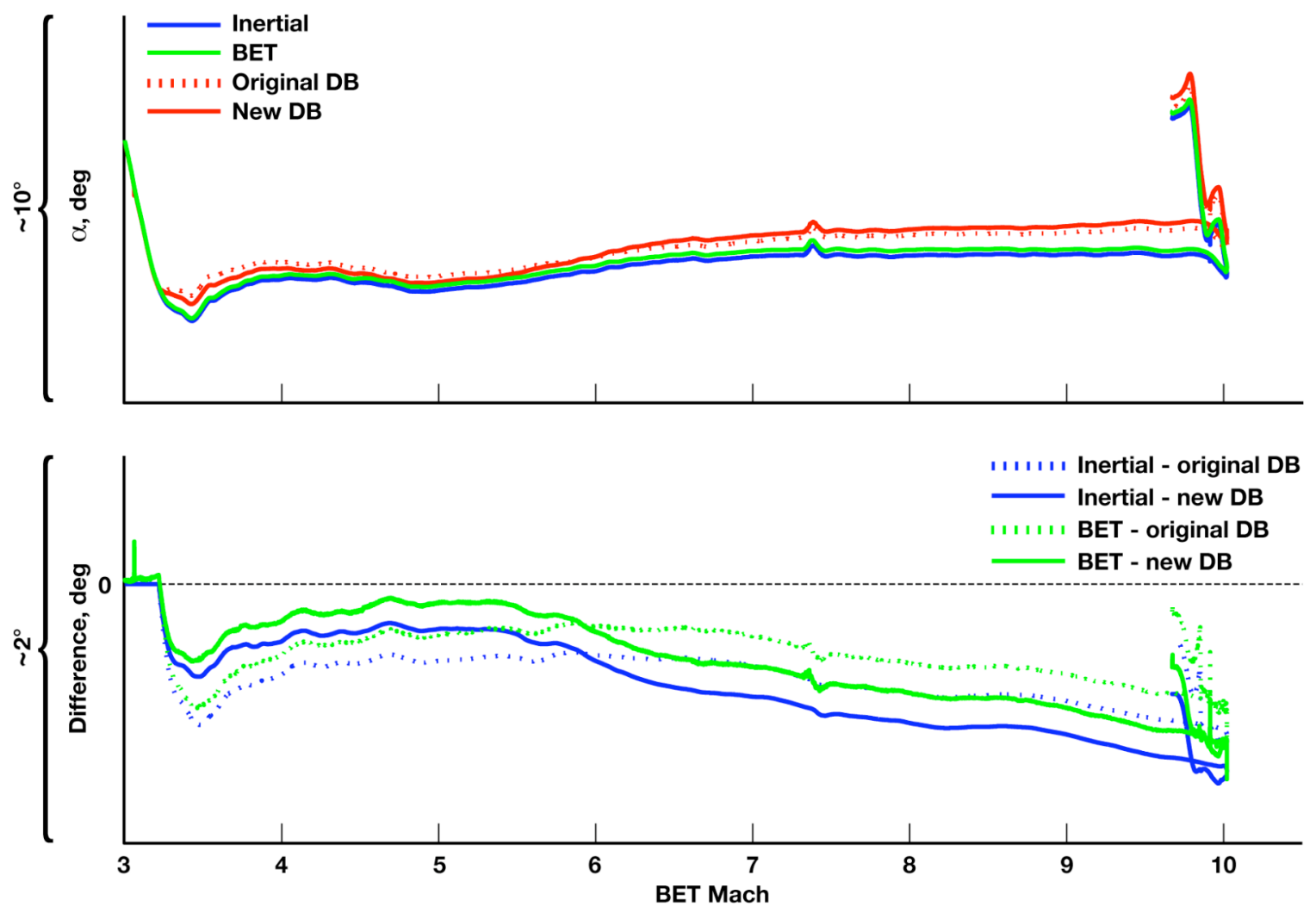

Figure 23. FADS $\alpha$ comparisons using the new and original databases for the Mach 10 mission ascent.
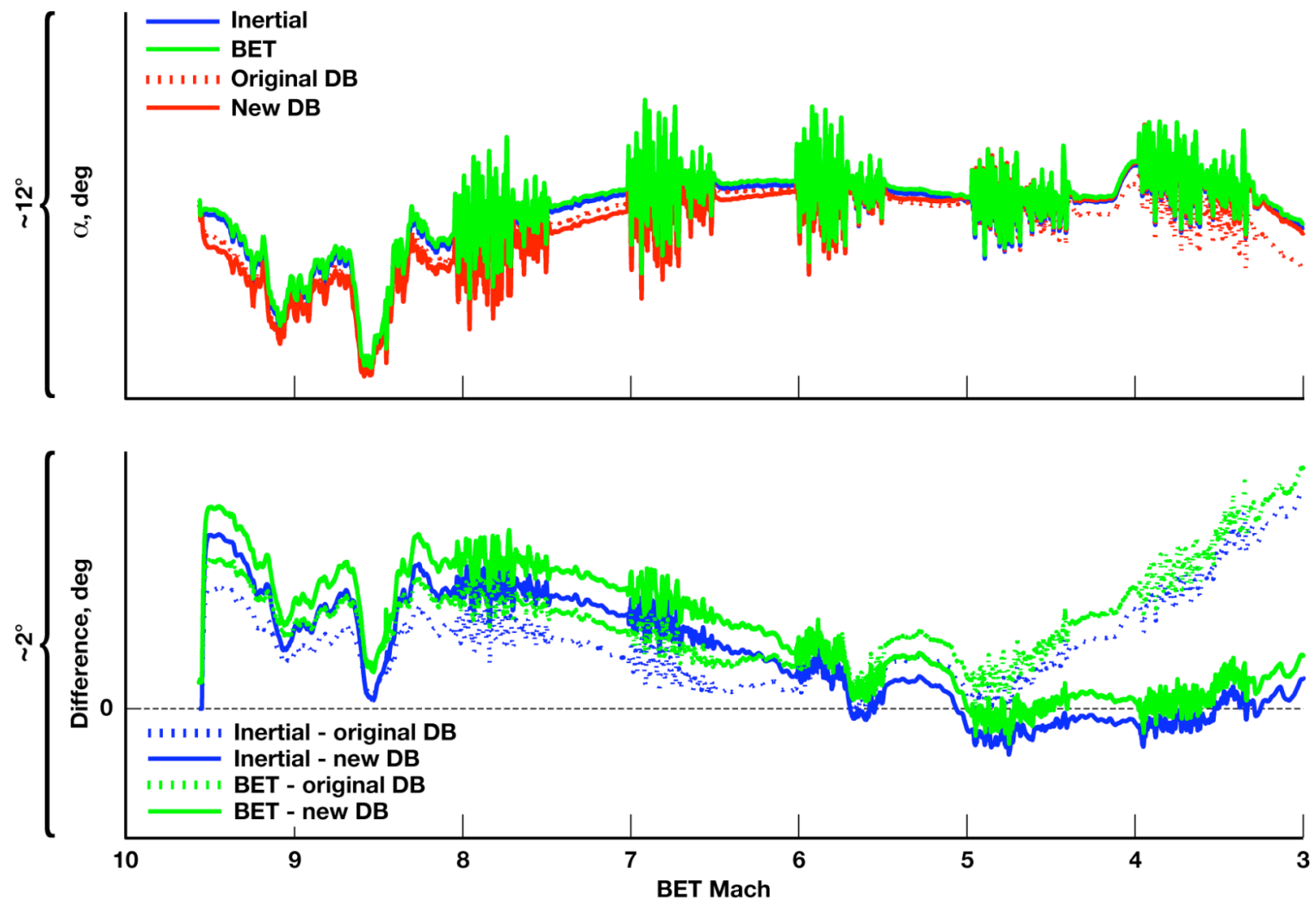

Figure 24. FADS $\alpha$ comparisons using the new and original databases for the Mach 10 mission descent. 


\section{Conclusion}

A flush airdata sensing (FADS) system was flight-tested on the X-43A. Real-time estimates of angle of attack $(\alpha)$ were generated by the FADS $\alpha$ estimation algorithm. The real-time algorithm performed well during both the Mach 7 and Mach 10 missions, with the FADS $\alpha$ estimate being used during the Mach 7 mission to aid the inertial estimate. The pressures measured at the FADS pressure ports compare well with database values generated from simple viscid and inviscid calculations, except for the lower aft port at the lower Mach numbers. An unexplained pressure difference was seen in the wind tunnel and flight data for the lower aft port as compared to theory. Ongoing research is being conducted to investigate the reason for the decreased pressure reading for the lower aft port. When the FADS pressure database and $\alpha$ estimation algorithm were updated with wind tunnel results, the estimated FADS $\alpha$ and port pressures agreed better overall with the flight results, and compared significantly better below approximately Mach 5. The FADS system data collected during the flight test of the X-43A demonstrated the feasibility of estimating $\alpha$ on a sharp-nosed hypersonic vehicle.

\section{References}

${ }^{1}$ Davis, M. C., Pahle, J. W., White, J. T., Marshall, L. A., Mashburn, M. J., and Franks, R., "Development of a Flush Airdata Sensing System on a Sharp-Nosed Vehicle for Flight at Mach 3 to 8," NASA/TM-2000-209017, May 2000.

${ }^{2}$ Freeman, D. C., Jr., Reubush, D. E., McClinton, C. R., Rausch, V. L., and Crawford, J. L., "The NASA Hyper-X Program," NASA/TM-1997-207243, Oct. 1997.

${ }^{3}$ Ferlemann, S. M., McClinton, C. R., Rock, K. E., and Voland, R. T., "Hyper-X Mach 7 Scramjet Design, Ground Test and Flight Results," AIAA-2005-3322, May 2005.

${ }^{4}$ X-43A Mishap Investigation Board, "Report of Findings: X-43A Mishap," Vol. I, May 2003.

${ }^{5}$ Marshall, L. A., Corpening, G. P., and Sherrill, R., "A Chief Engineer's View of the NASA X-43A Scramjet Flight Test," AIAA-2005-3332, May 2005.

${ }^{6}$ Marshall, L. A., Bahm, C., Corpening, G. P., and Sherrill, R., "Overview With Results and Lessons Learned of the X-43A Mach 10 Flight," AIAA-2005-3336, May 2005.

${ }^{7}$ Bahm, C., Baumann, E., Martin, J., Bose, D., Beck, R. E., and Strovers, B., "The X-43A Hyper-X Mach 7 Flight 2 Guidance, Navigation, and Control Overview and Flight Test Results," AIAA-2005-3275, May 2005.

${ }^{8}$ Baumann, E., Bahm, C., Strovers, B., and Beck, R., "The X-43A Mach 10 Mission Guidance and Control Updates, Rationale, and Flight Test Results," NASA/TM-2007-214610, Jan. 2007. Available from the former chief engineer, X-43 Project.

${ }^{9}$ Ohlhorst, C. W., Glass, D. E., Bruce, W. E., Lindell, M. C., Vaughn, W. L., Smith, R. W., Dirling, R. B., Jr., Hogenson, P. A., Nichols, J. M., Risner, N. W., Thompson, D. R., Kowbel, W., Sullivan, B. J., Koenig, J. R., and Cuneo, J. C., "Development of X-43A Mach 10 Leading Edges," IAC-05-D2.5.06, Oct. 2005.

${ }^{10}$ Morelli, E. A., Derry, S. D., and Smith, M. S., "Aerodynamic Parameter Estimation for the X-43A (Hyper-X) from Flight Data," AIAA-2005-5921, Aug. 2005.

${ }^{11}$ Baumann, E. A., "Tailored Excitation for Frequency Response Measurement Applied to the X-43A Flight Vehicle," NASA/TM-2007-214609, Jan. 2007.

${ }^{12}$ White, J. T., "Results of the HYPER-X Research Vehicle (HXRV) Flush Air Data Sensing (FADS) System Wind Tunnel Test (AEDC VA435)," HX-DFRC-0308, Dec. 2003.

${ }^{13}$ Karlgaard, C. D., Tartabini, P. V., Blanchard, R. C., Kirsch, M., and Toniolo, M. D., "Hyper-X Post-Flight-Trajectory Reconstruction," Journal of Spacecraft and Rockets, Vol. 43, No. 1, January-February 2006.

${ }^{14}$ Karlgaard, C. D., Martin, J. G., Tartabini, P. V., and Thornblom, M. N., "Hyper-X Mach 10 Trajectory Reconstruction," AIAA-2005-5920, Aug. 2005. 